\title{
Research on Direct Shear Strength Characteristics of Mechanically Biologically Treated Waste
}

\section{Zhenying Zhang ( $\nabla$ zhangzhenyinga@163.com )}

Zhejiang Sci-Tech University https://orcid.org/0000-0002-4076-1926

Jiahe Zhang

Zhejiang Sci-Tech University

\section{Qiaona Wang}

Zhejiang Sci-Tech University

\section{Min Wang}

Zhejiang Sci-Tech University

\section{Chengyu Nie}

Zhejiang Sci-Tech University

\section{Research Article}

Keywords: Mechanically biologically treated municipal solid waste, Shearing displacement rate, landfill depth, shear strength, Shear strength characteristics, Shear strength model

Posted Date: March 9th, 2021

DOI: https://doi.org/10.21203/rs.3.rs-207864/v1

License: (c) (i) This work is licensed under a Creative Commons Attribution 4.0 International License.

Read Full License 

treated Waste

4 Zhenying Zhang ${ }^{\mathrm{a}}{ }^{*}$, Jiahe Zhang $^{\mathrm{a}}$, Qiaona Wang ${ }^{\mathrm{a}}$, Min Wang ${ }^{\mathrm{a}}$, Chengyu Nie ${ }^{\mathrm{a}}$

5 aSchool of Civil Engineering and Architecture, Zhejiang Sci-Tech University, $6 \quad$ Hangzhou 310018, China

8 *Correspondence should be addressed to Zhenying Zhang; zhangzhenyinga@ 163.com 9

10 Abstract: Mechanically biologically treated (MBT) waste has significant 11 characteristics such as high stability and low moisture content, which can reduce 12 water, soil, and gas pollution in subsequent treatments. This pre-treatment method is 13 environmentally friendly and sustainable, and has become a popular research topic in 14 the field of environmental geotechnical engineering. Using a direct shear test 15 apparatus and five shearing rates $(0.25,1,5,10$, and $20 \mathrm{~mm} / \mathrm{min})$, the shear strength 16 characteristics of MBT waste at the Hangzhou Tianziling (HT) Landfill were studied. 17 The results indicate: (1). With the increase in horizontal shear displacement, the shear 18 stress of MBT waste gradually increases without a peak stress phenomenon, which is 19 a displacement hardening curve; (2). The shear strength increased with an increase in 20 the shearing displacement rate, and the sensitivity coefficient was $0.64-2.66$. (3). The 
21 shear strength, shearing rate, and normal stress correlation model are established, and

22 the model has a high degree of fit with the overall experimental data; (4). Cohesion

23 (c), internal friction angle $(\varphi)$, and the logarithm of the shearing rate are linear; (5).

24 The range of $c$ of MBT waste is $22.32-39.51 \mathrm{kPa}$, and $\varphi$ is $64.24-.68 .52^{\circ}$. Meanwhile,

25 the test data are compared with the test data in the literature, and the shear 26 characteristics of HT-MBT waste are discussed. The research results of this study can 27 provide a reference for the stability calculation of MBT landfills.

28 Keywords: Mechanically biologically treated municipal solid waste, Shearing 29 displacement rate, landfill depth, shear strength, Shear strength characteristics, Shear 30 strength model

\section{Introduction}

Increasing population and rapid urbanisation have consequently led to an increase

34 in the output of municipal solid waste (MSW) (Guerrero et al. 2013, Eskandari et al.

35 2016). Due to the vast amount of solid waste produced, pre-treatment processes for 36 solid waste have gradually attracted attention. In April 1999, the European Union 37 Landfill Directive (99/31/EC) defined the design and operation standards of landfills 38 and mandatory requirements to reduce the biodegradable materials in MSW entering 39 landfills. Under this directive, member states adopt different strategies to transfer 40 organic matter in domestic waste from landfills, such as converting the biodegradable 
41 component into fertiliser, incinerating MSW, and then proceeding with landfilling or 42 recycling the residue from incineration. Member states have also increased their focus 43 on pre-treatment technologies for untreated MSW, with mechanically biologically treated (MBT) waste demonstrating the most favourable characteristics. MBT technology is primarily divided into two parts: first, mechanical processing (crushing, sieving, centrifugation, or selection) is used for separation of biodegradable and non-biodegradable materials and large-size materials are sieved or shredded. Next, biological treatment (anaerobic digestion and leaching hydrolysis, etc.) accelerates the degradation of biomass in MSW. Compared with MSW that is directly landfilled, MBT reduces the amount of biodegradable materials and their

51 biodegradability, thereby reducing environmental pollution caused by the discharge of 52 leachate and greenhouse gases. Therefore, this technology is applied in many 53 European cities (Kuehle-Weidemeier 2004). In several cases, the residue produced by 54 MBT does not have a high enough economic value making it unsuitable for use or a disposal method other than landfill (Archer et al. 2005). However, because MBT converts MSW into another material, the product from this pre-treatment varies from 57 its parent material in terms of characteristics. Thus, the physical properties of MSW 58 (particle size, composition, moisture content, density, and void ratio) to be discarded in landfills are fundamentally changed (Zhang et al. 2018a), consequently changing its mechanical properties, such as shear strength, compression, and consolidation. This 
61 greatly affects the strength, stiffness, and stability of the landfill (Jones \& Dixon, 62 2015). The design of the slope and pile stability calculation of the MBT landfill site 63 should be based on its mechanical characteristics to ensure the safety of the project. Many researchers (Landva and Clark 1990, Singh and Murphy 1990, Kavazanjian et al. 1995, Gabr and Valero 1995, Manassero et al. 1996, Jones et al. 1997, Machado et al. 2002, Stark et al. 2009, Bray et al. 2009, Reddy et al. 2009a, Bareither et al. 2012, Zhang et al. 2014, Zhang et al. 2015, Zekkos and Fei 2016, Abreu and Vilar 2017, Fei and Zekkos 2017, Karimpour-Fard 2018, Falamaki et al. 2019, Keramati et al. 2020) conducted a shear strength test study on MSW, and conducted an instability failure simulation model analysis on an existing landfill. However, unlike MSW, 71 research on the shear strength of MBT waste appears to be more limited. Fucale 72 (2005), Mahler \& Neto (2006), and Fucale et al. (2007) used direct shear (DS) 73 equipment to analyse the influence of fibre on the strength of MBT waste. Fucale 74 (2005) mixed MSW and MBT waste with different percentages of fibres to study the effect of randomly distributed plastic fibres on the mechanical properties of the material, and to verify the possible similarities between these properties. Mahler \& 77 Neto (2006) observed that the fibre composition of MBT waste has a substantial 78 influence on the shear strength of MBT waste. This is because, although MBT waste is characterised by a coarse material with non-sticky particle behaviour, it is due to the tensile strength of the fibre is high; it may still show a high false viscosity value. 
81 Fernando et al. (2009) and Fernando and Sudarshana (2011) conducted DS

82 experiments on MBT waste with different reinforcement contents and compared the

83 strength of MSW. Experimental results show that MBT waste is stronger than MSW.

84 Petrovic and Bauer (2011) conducted experimental research and numerical

85 simulations on the mechanical behaviour of MBT waste with different moisture

86 contents. Bhandari and Powrie (2013) conducted triaxial experiments on MBT waste

87 with different particle sizes and shapes to study the stress-strain-strength

88 characteristics of MBT waste. Pimolthai and Wagner (2014) used DS equipment to

89 test the shear strength of MBT waste with a particle size of less than $10 \mathrm{~mm}$. Babu et

90 al. (2015) used the DS test, and small-scale triaxial text and large-scale triaxial text

91 apparatus were used for experiments to comprehensively test the shear strength

92 characteristics of MBT waste. Fucale et al. (2015) experimentally found that the

93 reinforcement phases (plastics, textiles, fibres, etc.) present in landfills have a great

94 influence on the various characteristics (including strength) of MBT waste. Relevant

95 literature on the shear strength characteristics of MBT waste is presented in Table 1.

96

97 Table 1. Reference summary.

\begin{tabular}{|c|c|c|c|c|}
\hline \multirow[t]{2}{*}{ Reference } & Country & $\begin{array}{l}\text { Testing method and } \\
\text { sample size }(\mathrm{mm})\end{array}$ & $\begin{array}{l}\text { Displacement or strain at the } \\
\text { shearing } \\
\text { resistance considered and }\end{array}$ & $c(\mathrm{kPa}) \quad \varphi\left({ }^{\circ}\right)$ \\
\hline & & & vertical pressure $(\mathrm{kPa})$ & \\
\hline
\end{tabular}




\begin{tabular}{|c|c|c|c|c|c|}
\hline Fucale (2005) & Germany & L-DS, $100 \times 100 \times 30$ & $\mathrm{PD}(18 \mathrm{~mm}), 100-300$ & 18.7 & 10.2 \\
\hline Mahler and Neto (2006) & Brazil & L-DS, NA & PD (12mm), 25-100 & NA & NA \\
\hline \multirow[t]{2}{*}{ Fernando et al. (2009) } & United Kingdom & L-DS, NA & PD (4\%), 100 & NA & NA \\
\hline & & & PD (3\%), 50 & NA & NA \\
\hline Fernando (2011) & United Kingdom & L-DS, NA & NA & NA & NA \\
\hline Petrovic and Bauer (2011) & Croatia & L-DS, NA & PD (NA), 36-180 & NA & $31-50$ \\
\hline $\begin{array}{l}\text { Bhandari and Powrie } \\
\text { (2013) }\end{array}$ & NA & L-TT, NA & PD (35\%), 25-200 & NA & NA \\
\hline Pimolthai and Wagner & Luxembourg & L-DS, 94(D) and 20(H) & PS, 20-100 & 12.8 & 36.5 \\
\hline \multirow[t]{2}{*}{ (2014) } & Germany & & & 9.0 & 38.6 \\
\hline & Thailand & & & 5.4 & 31.9 \\
\hline Babu et al. (2015) & India & L-DS, $60 \times 60 \times 30$ & $\mathrm{PD}(20 \%), 50-150$ & 12 & 40 \\
\hline \multirow[t]{3}{*}{ Fucale et al. (2015) } & Switzerland & L-DS, $100 \times 100 \times 150$ & PD (20\%), $100-300$ & 16.0 & 40.1 \\
\hline & & & & 34.7 & 45.4 \\
\hline & & & & 63.1 & 48.1 \\
\hline L laboratory & ests, DS direct sh & ear, TT trixial text, PS $p$ & eak stress, PD peak di & NA not & \\
\hline 99 available. & & & & & \\
\hline
\end{tabular}

101 Few studies exist on the relationship between MBT waste at different shearing

102 rates, landfill depths, and shear strength. This study considers the shearing rate,

103 simulated landfill depth, and other factors, and systematically studies MBT shear

104 strength characteristics. The theoretical model of shear strength prediction is

105 established, and the variation range of the shear strength parameters is obtained. The

106 findings of this work provide basic data and strength models for the design and 
107 instability and destruction prediction of MBT landfills.

108

109 2. Materials, device, and process

$110 \quad 2.1$ Materials

111 Hangzhou is the largest city in Zhejiang province with a population of

112 approximately 10.36 million. At least $12,000 \mathrm{t}$ of domestic waste are generated daily,

113 and part of the waste is transported to the Hangzhou Tianziling (HT) Landfill. The

114 HT-MSW Treatment Plant is divided into two parts: the first (closed) and second (in

115 operation) landfills. The second landfill is expanded vertically and horizontally on a

116 one-field basis. Its total storage capacity is 22.02 million $\mathrm{m}^{3}$, which can absorb 24.05

117 million t of MSW and treat 1,940-4,000 t of waste daily. The geographical location of 118 the HTL is shown in Figure 1.

119 


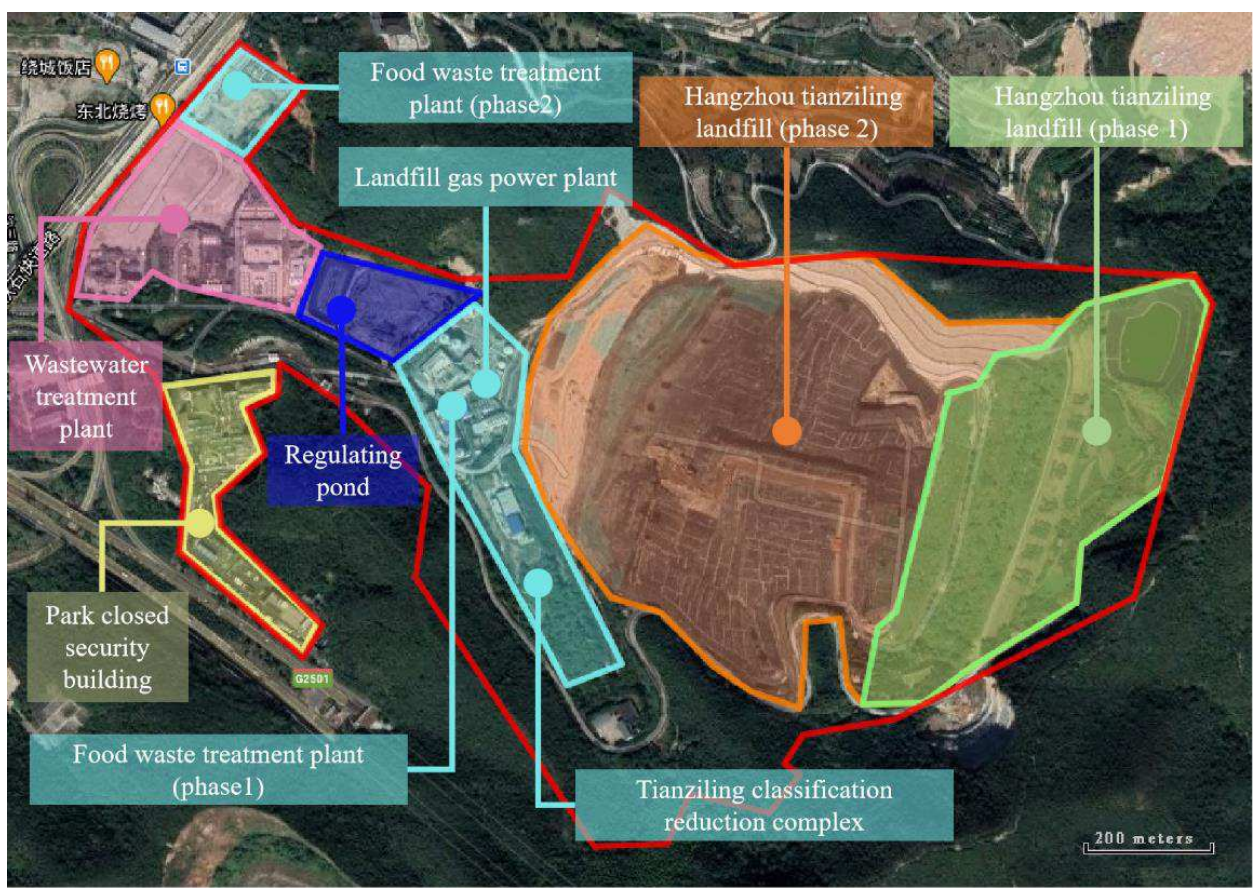

Figure 1 Floor plan of Hangzhou Tianziling Landfill, China.

The China Hangzhou Environment Group introduced MBT technology from Germany and produced MBT waste through several processes. First, the fresh MSW is crushed and sieved in a rotating drum screen with an aperture of $120 \mathrm{~mm}$. Through the screen, large-sized materials (mainly cardboard, plastic, and textiles) are manually screened for recycling. The metal and material passing through the screen are separated by a magnetic separation method, and the remaining small-sized materials enter the reactor for hydrolysis treatment. Subsequently, the solid-phase hydrolysate with a moisture content of more than $40 \%$ is usually transferred to a drying chamber for biological drying. After biological drying for $\sim 9 \mathrm{~d}$, it eventually becomes MBT 
132 waste. The test materials were obtained from the MBT factory, placed in sealed plastic

133 drums, and directly transported to the Environmental Geotechnical Materials

134 Laboratory of Zhejiang Sci-Tech University. The original appearance of the MBT 135 materials is shown in Figure 2.

136

137

138

139

140

141 Table 2, which shows that MBT waste includes paper, plastic, rubber, textiles, wood,

142 stone, ceramics, glass, metal, fine-grained soil, and other visually indistinguishable

143 materials. Judging from the MBT waste, the most important components in MBT

144 waste are plastic and rubber, and their combined mass is 1,216.5 g, accounting for

$14523.3 \%$ of the total dry mass. This is because they are not easily biodegradable and 
146 there is poor national recycling awareness. The quantity of the paper is $0 \mathrm{~g}$, mainly

147 because the paper is broken during the MBT process. After degradation, it is not the

148 correct size of paper or easy to identify. The residue is classified into an undefined

149 particle size. The moisture content of general waste is $60-80 \%$ (Gao et al. 2015), and

150 the moisture content of MBT waste is $20 \%$, which is significantly lower than that of

151 general waste.

152

153 Table 2 Composition and physical properties of MBT waste sample

\begin{tabular}{|c|c|c|c|c|c|c|c|c|c|c|}
\hline \multicolumn{9}{|c|}{ Composition (percentage by dry weight/g) } & \multirow{2}{*}{$\begin{array}{l}\text { Specific } \\
\text { gravity }\end{array}$} & \multirow{2}{*}{$\begin{array}{l}\text { Moisture } \\
\text { content }(\%)\end{array}$} \\
\hline Paper & $\begin{array}{l}\text { Plastic \& } \\
\text { rubber }\end{array}$ & Textile & Wood & $\begin{array}{l}\text { Stones \& } \\
\text { ceramics }\end{array}$ & Glass & Metal & $\begin{array}{l}\text { Undefined } \\
>5 \mathrm{~mm}\end{array}$ & $\begin{array}{l}\text { Fines } \\
<5 \mathrm{~mm}\end{array}$ & & \\
\hline 0 & 1216.5 & 255.4 & 240.2 & 737.5 & 1076 & 139 & 465.9 & 1080.2 & 1.53 & 20.0 \\
\hline
\end{tabular}

154

155

2.2 Direct shear test device

157 In this study, a DS apparatus (Figure 3) was used. This device uses a stepper

158 motor, continuous variable, and can input any speed within the range of the test

159 protocol for shearing. Furthermore, the device has a relatively large shear box with a

160 diameter of $185 \mathrm{~mm}$ (upper and lower shear box heights of 40 and $20 \mathrm{~mm}$,

161 respectively). The instrument loading device includes horizontal and vertical loading.

162 The maximum horizontal load is up to $50 \mathrm{kN}$, and the maximum vertical load is 57.12 
$163 \mathrm{~kg}$ to generate a vertical stress of up to $400 \mathrm{kPa}$. The shear displacement and vertical

164 deformation of the sample were measured using two displacement meters.

165

166

167

\section{8}

169

170

171

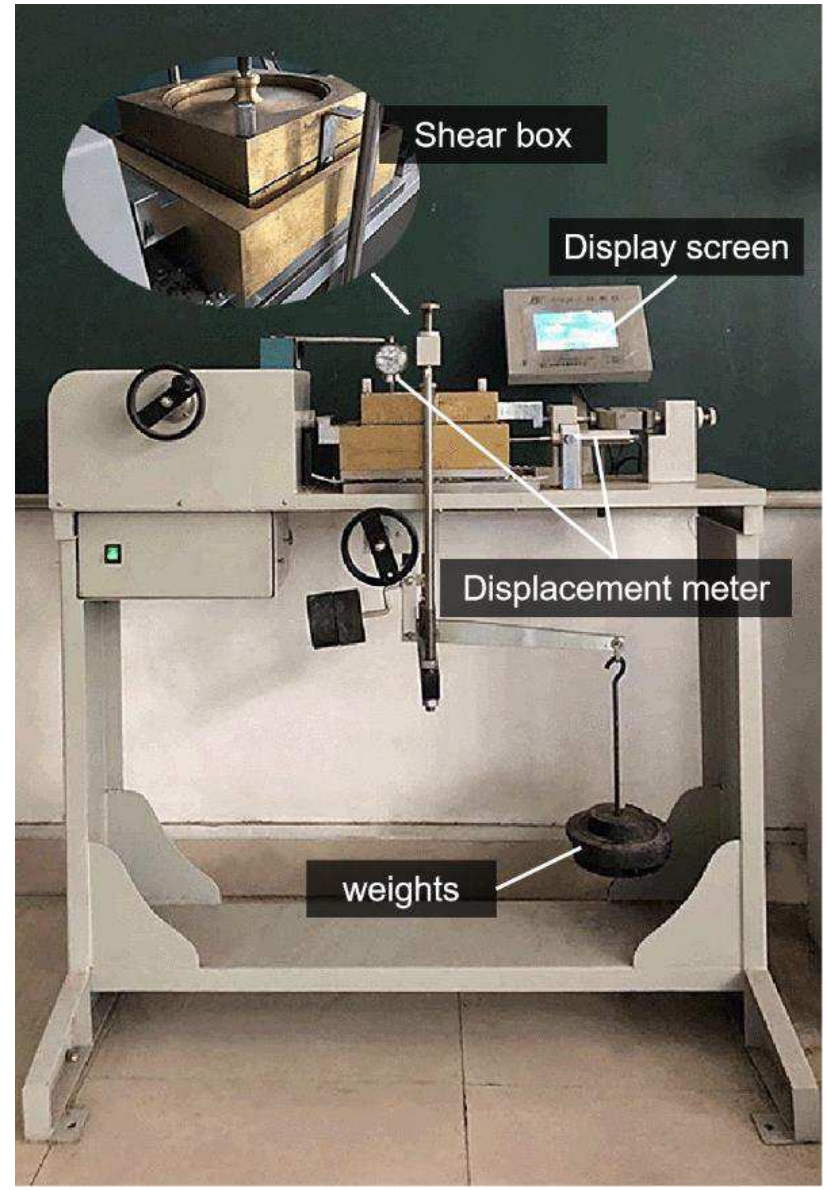

Figure 3 Direct shear test apparatus.

\subsection{Text process}

The horizontal displacement applied by the motor generates shear stress at a constant rate, and the shearing rate adjustment range is between 0.01 and 99.99 
$172 \mathrm{~mm} / \mathrm{min}$. Researchers (Fard et al. 2015, Zhan et al. 2015, Abreu et al. 2017) have

173 conducted experiments on MSW or MBT waste and set a shearing displacement rate

174 ranging from 0.2 to $19 \mathrm{~mm} / \mathrm{min}$; however, these studies did not consider the effect of

175 shearing displacement rate on the material. Therefore, this study covers the above-

176 mentioned rates and selects five shearing rates for comparison experiments: $0.25,1,5$,

17710 , and $20 \mathrm{~mm} / \mathrm{min}$. The waste in the landfill is gradually piled up in layers during the

178 landfill process, because of which, the landfill body will undergo compression and

179 deformation accompanied by slipping instability allowing it to be simulated and

180 studied. There were changes in the shear strength parameters of MBT waste with

181 buried depth (10-100 m). The preparation of MBT waste samples included chopping

182 it into particles $<23 \mathrm{~mm}$ to ensure that the ratio of the maximum material particle size

183 to the diameter of the shear box did not exceed 1:8 (CJJ/T 2013) (Figure 4). To ensure

184 that the moisture content of each sample was consistent, the MBT waste sample with

185 a moisture content of $20 \%$ was prepared before the DS test. The specific steps were as

186 follows: a 700-g MBT waste sample was placed into an oven at $65^{\circ} \mathrm{C}$, the sample was

187 dried for $24 \pm 1 \mathrm{~h}$, to a constant weight. Then, $140 \mathrm{~g}$ of purified water was used

188 tosprayed evenly on the MBT waste soil with a watering can and the sample was

189 turned the continuously. Finally, the sample was stewing for $24 \pm 1 \mathrm{~h}$. 


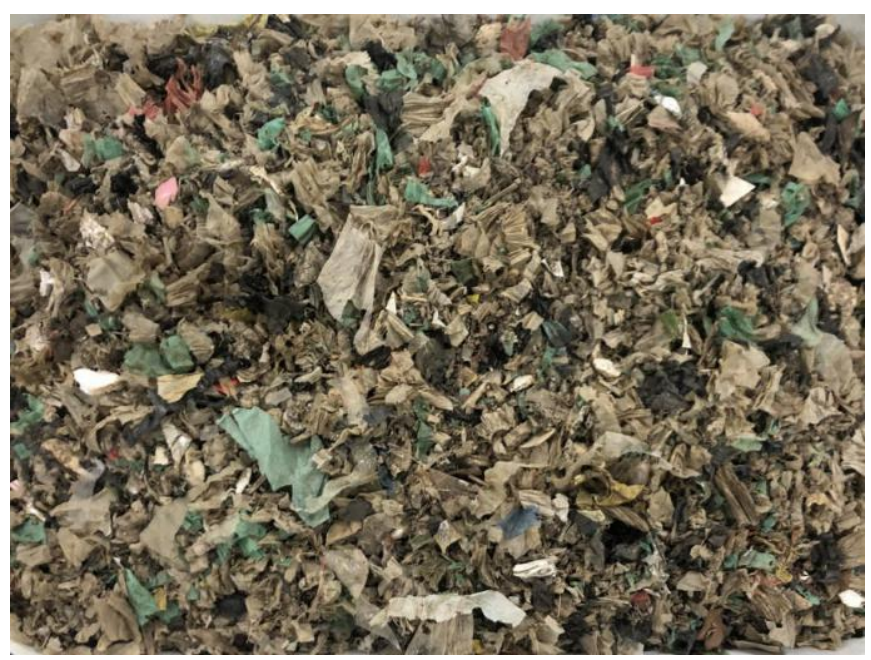

Figure 4 MBT waste test materials.

195 tamping hammer was used to evenly compact the sample to ensure the same vertical

196 settlement in the same plane to reach an initial unit weight of $4 \mathrm{kN} / \mathrm{m}^{3}$. Table 3 lists all

197 the samples and test parameters used in this study. A total of 50 samples were tested.

198 The vertical stresses were 40, 80, 120, 160, 200, 240, 280, 320, 360, and $400 \mathrm{kPa}$.

199 After compressing the sample for $1440 \pm 60$ min under continuous vertical pressure,

200 the shearing test was performed. Finally, the specimens were sheared at constant and 201 slow $(0.25,1$, and $5 \mathrm{~mm} / \mathrm{min})$ or fast $(10$ and $20 \mathrm{~mm} / \mathrm{min})$ shearing rates. The 202 horizontal load was recorded every time the specimen produced $1 \%$ shear horizontal 203 displacement. The test ended when the ratio of the shear horizontal displacement to 204 the sample diameter reached $20 \%$. 
205 Table 3 Specimen and test parameters.

\begin{tabular}{|c|c|c|c|c|c|c|}
\hline Specimen & Vertical pressure & Vertical & Total unit & Shearing rate & Shear test & Temperature \\
\hline \multirow[t]{3}{*}{ number } & during compressing & pressure & weight prior & $(\mathrm{mm} / \mathrm{min})$ & duration (min) & $\left({ }^{\circ} \mathrm{C}\right)$ \\
\hline & $(\sigma, \mathrm{kPa})$ & duration & to shearing & & & \\
\hline & & $(\min )$ & $\left(\gamma, \mathrm{kN} / \mathrm{m}^{3}\right)$ & & & \\
\hline
\end{tabular}

\begin{tabular}{|c|c|c|c|c|c|c|}
\hline DS1-1 & 40 & 1440 & 5.12 & 0.25 & 149.1 & 28.5 \\
\hline DS1-2 & 80 & 1380 & 6.05 & 0.25 & 154.2 & 29.3 \\
\hline DS1-3 & 120 & 1380 & 6.31 & 0.25 & 154.1 & 28.7 \\
\hline DS1-4 & 160 & 1380 & 6.58 & 0.25 & 154.5 & 28.6 \\
\hline DS1-5 & 200 & 1350 & 6.81 & 0.25 & 154.1 & 28.9 \\
\hline DS1-6 & 240 & 1380 & 7.01 & 0.25 & 154.1 & 28.7 \\
\hline DS1-7 & 280 & 1380 & 7.25 & 0.25 & 154.1 & 28.9 \\
\hline DS1-8 & 320 & 1380 & 7.44 & 0.25 & 154.1 & 29.1 \\
\hline DS1-9 & 360 & 1380 & 7.62 & 0.25 & 154.5 & 29.3 \\
\hline DS1-10 & 400 & 1350 & 7.77 & 0.25 & 155.9 & 29.1 \\
\hline DS2-1 & 40 & 1440 & 5.12 & 1 & 37.2 & 26.2 \\
\hline DS2-2 & 80 & 1440 & 6.01 & 1 & 37.8 & 26.5 \\
\hline DS2-3 & 120 & 1440 & 6.32 & 1 & 37.1 & 26.6 \\
\hline DS2-4 & 160 & 1380 & 6.57 & 1 & 37.5 & 27.1 \\
\hline DS2-5 & 200 & 1560 & 6.81 & 1 & 38.5 & 26.5 \\
\hline DS2-6 & 240 & 1380 & 7.02 & 1 & 39.2 & 26.8 \\
\hline DS2-7 & 280 & 1440 & 7.22 & 1 & 38.6 & 26.5 \\
\hline DS2-8 & 320 & 1380 & 7.43 & 1 & 42.1 & 26.5 \\
\hline DS2-9 & 360 & 1380 & 7.62 & 1 & 37.8 & 27.1 \\
\hline DS2-10 & 400 & 1380 & 7.71 & 1 & 38.0 & 26.8 \\
\hline DS3-1 & 40 & 1380 & 5.15 & 5 & 8.1 & 28.6 \\
\hline DS3-2 & 80 & 1440 & $6 . .11$ & 5 & 7.8 & 28.5 \\
\hline DS3-3 & 120 & 1400 & 6.38 & 5 & 7.9 & 28.7 \\
\hline DS3-4 & 160 & 1440 & 6.58 & 5 & 7.9 & 28.8 \\
\hline DS3-5 & 200 & 1380 & 6.90 & 5 & 7.7 & 29.1 \\
\hline
\end{tabular}




\begin{tabular}{|c|c|c|c|c|c|c|}
\hline DS3-6 & 240 & 1440 & 7.12 & 5 & 7.7 & 28.7 \\
\hline DS3-7 & 280 & 1440 & 7.25 & 5 & 7.7 & 28.7 \\
\hline DS3-8 & 320 & 1380 & 7.48 & 5 & 7.7 & 29.3 \\
\hline DS3-9 & 360 & 1380 & 7.67 & 5 & 7.8 & 28.9 \\
\hline DS3-10 & 400 & 1440 & 7.79 & 5 & 8.0 & 28.8 \\
\hline DS4-1 & 40 & 1380 & 5.11 & 10 & 3.9 & 26.9 \\
\hline DS4-2 & 80 & 1440 & 6.01 & 10 & 4.0 & 26.7 \\
\hline DS4-3 & 120 & 1400 & 6.32 & 10 & 4.0 & 27.6 \\
\hline DS4-4 & 160 & 1400 & 6.58 & 10 & 4.0 & 26.5 \\
\hline DS4-5 & 200 & 1440 & 6.80 & 10 & 4.0 & 27.1 \\
\hline DS4-6 & 240 & 1440 & 7.02 & 10 & 4.0 & 26.8 \\
\hline DS4-7 & 280 & 1400 & 7.23 & 10 & 4.0 & 26.9 \\
\hline DS4-8 & 320 & 1440 & 7.43 & 10 & 4.0 & 27.3 \\
\hline DS4-9 & 360 & 1440 & 7.62 & 10 & 3.9 & 27.1 \\
\hline DS4-10 & 400 & 1400 & 7.84 & 10 & 4.0 & 27.5 \\
\hline DS5-1 & 40 & 1440 & 5.21 & 20 & 2.0 & 27.5 \\
\hline DS5-2 & 80 & 1440 & 6.09 & 20 & 2.0 & 27.8 \\
\hline DS5-3 & 120 & 1440 & 6.35 & 20 & 2.0 & 27.5 \\
\hline DS5-4 & 160 & 1440 & 6.61 & 20 & 2.0 & 28.1 \\
\hline DS5-5 & 200 & 1380 & 6.90 & 20 & 2.0 & 28.3 \\
\hline DS5-6 & 240 & 1440 & 7.01 & 20 & 2.0 & 28.3 \\
\hline DS5-7 & 280 & 1440 & 7.25 & 20 & 2.0 & 28.1 \\
\hline DS5-8 & 320 & 1440 & 7.44 & 20 & 2.0 & 28.5 \\
\hline DS5-9 & 360 & 1380 & 7.63 & 20 & 2.0 & 28.7 \\
\hline DS5-10 & 400 & 1440 & 7.92 & 20 & 2.0 & 28.3 \\
\hline
\end{tabular}

206 Note: DS - direct shear test.

\section{3. Results and analysis}

209 3.1 Consolidation phase

210 During the consolidation and compression stages, the specimen underwent 
211 compression deformation. However, due to the low organic content and low moisture 212 content of MBT waste, no drainage occurred during consolidation. The relationship 213 between the porosity ratio of the sample and logarithm of the vertical pressure in the 214 consolidation and compression stages is shows that as the vertical pressure increases, 215 the void ratio gradually decreases (Figure 5); the relationship can be fitted into a 216 straight line, the slope of the straight line (compression index) is 1.14 , and the sample 217 has high compressibility. Because the initial unit weight of the sample is $4 \mathrm{kN} / \mathrm{m}^{3}$, 218 when the vertical pressure increased from 40 to $400 \mathrm{kPa}$, it can simulate the self219 weight stress of MBT waste from $10 \mathrm{~m}$ to $100 \mathrm{~m}$. The weight of the MBT waste 220 material is comparable to the simulated landfill depth; the relationship is shown in 221 Figure 6. Figure 6 shows that as the self-weight stress increased, the unit weight of the 222 material increased from 4.00 to $7.84 \mathrm{kN} / \mathrm{m}^{3}$. The relationship between the porosity 223 ratio of MBT waste materials and simulated landfill depth is shown in Figure 7. 224 Figure 7 shows that the porosity ratio of MBT waste is generally larger than that of 225 MSW, and the porosity ratio of deep MBT waste is close to that of shallow MSW 226 waste. 


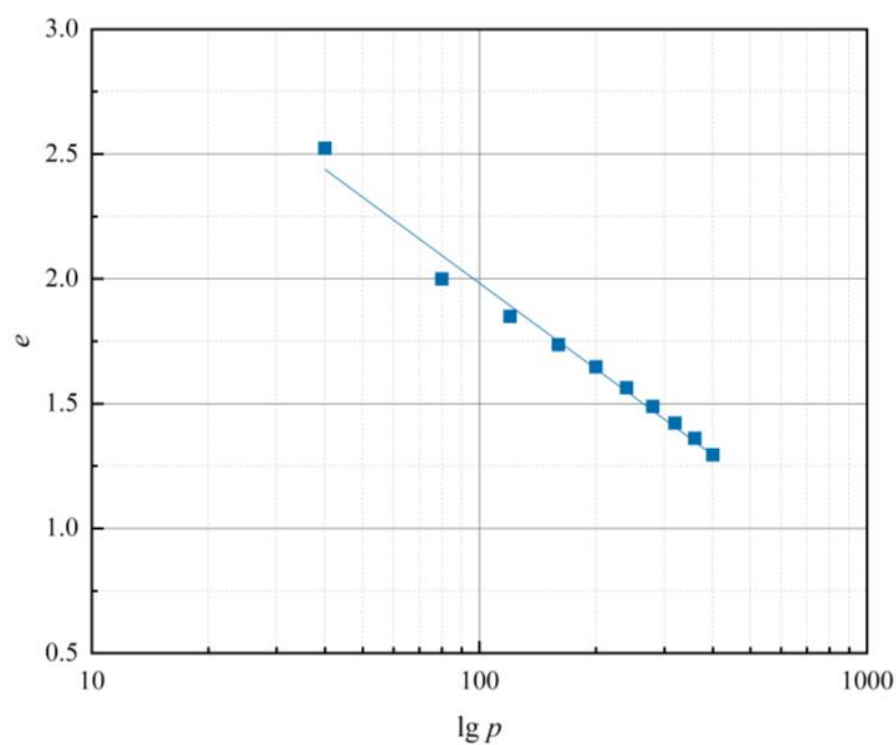

Figure 5 The relationship between the porosity ratio (e) and the logarithm of vertical pressure $(\lg \mathrm{p})$.

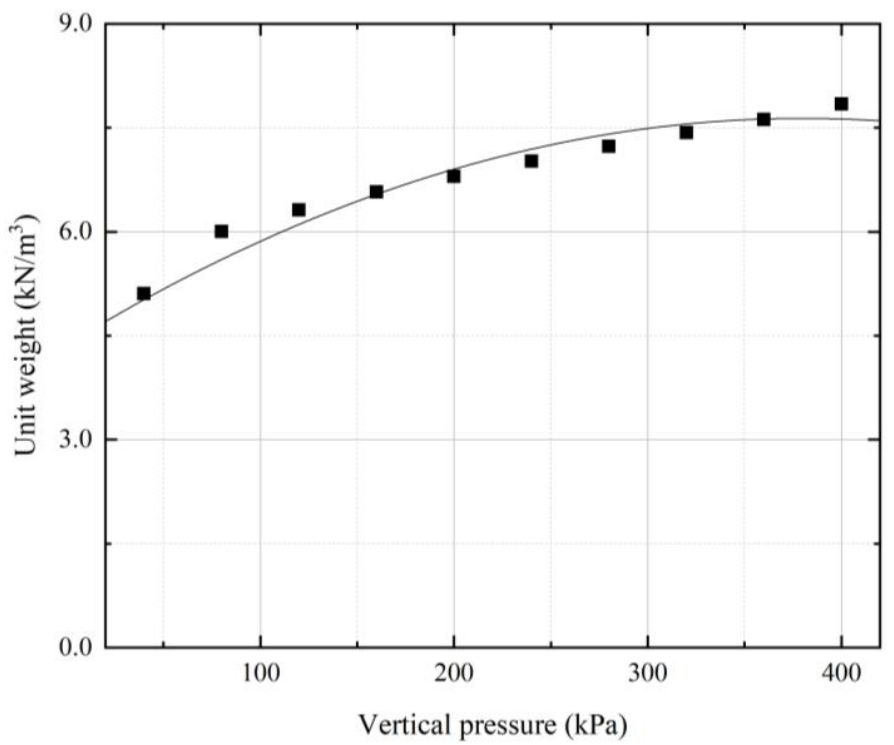

Figure 6 The relationship between the unit weight of the sample and the vertical pressure. 


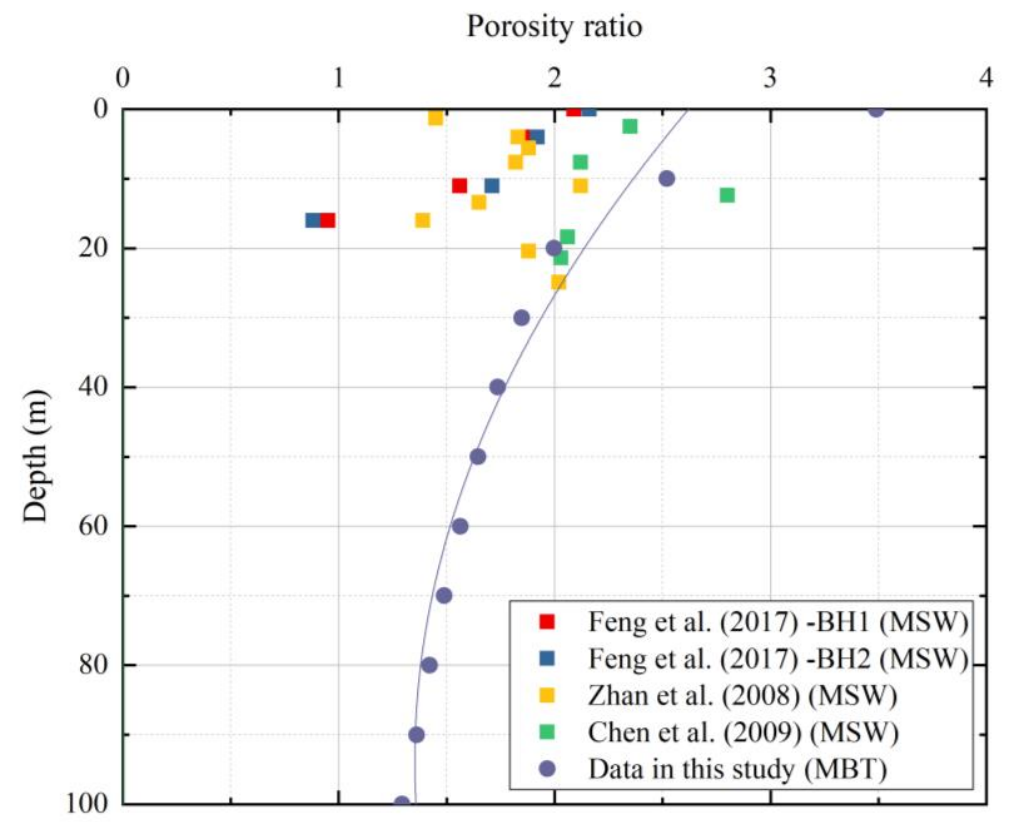

Figure 7 The porosity ratio of MSW and MBT waste varies with depth.

\subsection{Shear stress-displacement behaviour}

In this study, the DS stress-horizontal displacement graphs of all specimens show

238 strain hardening, which is illustrated with a shearing rate of $5 \mathrm{~mm} / \mathrm{min}$ (Figure 8). In

239 all tests, the shear stress continued to increase until the horizontal displacement 240 reached $37 \mathrm{~mm}$ (the ratio of horizontal displacement to sample diameter reached $24120 \%$ ). This is because the maximum displacement of the test equipment is $40 \mathrm{~mm}$;

242 therefore, the test must be interrupted when the horizontal displacement of the sample 243 reaches $37.5 \pm 0.5 \mathrm{~mm}$. The value range of the horizontal displacement is the same as

244 that performed by Zhan et al. (2008), Bray et al. (2009), Reddy et al. (2009a), Reddy 
245 et al. (2009b), and Feng et al. (2017). The test settings are similar, and the maximum

246 horizontal displacement values are all less than 35\%. Therefore, even under relatively

247 large displacements, displacement hardening is a common phenomenon in MBT 248 waste.

249 The shear stress-horizontal displacement curve of the sample shows an upward 250 convex trend. As the horizontal displacement increases, the shear stress increases 251 rapidly. When the horizontal displacement of the specimen reached $9.25 \mathrm{~mm}$ (the ratio 252 of horizontal displacement to sample diameter reached 5\%), the growth rate of the 253 shear stress changed from high speed to stable. The shear stress-horizontal 254 displacement relationship of MBT waste is similar to that of general MSW (Zhang 255 2018c). The main reason for this phenomenon is that initially, the shear strength of the 256 material is borne by the fine-grained aggregate, and as the horizontal displacement 257 increases, it quickly rises to the ultimate shear strength of the aggregate. 258 Subsequently, reinforced materials such as plastics are used as the main shear 259 resistance components, and fibrous materials such as plastics will be stretched and 260 deformed under the action of shear load. However, these materials are not easily 261 broken by instantaneous breakage during the stretching process owing to their good 262 toughness; however, like elastic materials, there is still a process of yielding before 263 failure, showing reinforcement characteristics.

264 In this study, 10 different vertical pressures were applied to the sample to 
265 simulate the landfill depth of MBT waste of 10-100 m. It can be clearly observed in 266 Figure 8 that the shear strength obtained by the shear test of MBT waste increases 267 with the increase in vertical pressure (landfill depth), which is different from the 268 decrease in MSW shear strength with increasing depth (Cho et al., 2011; Feng et al., 269 2017). The main reason for this is that the composition of the material and physical 270 properties of the material will change with an increase in the MSW landfill depth. 271 Compared with deep MSW, shallow MSW has high degradability, high organic 272 content, and relatively low water content; therefore, it has better shear performance in 273 the shear test (Karimpour-Fard 2018). However, after MBT, as the depth of the 274 landfill increases, the material content and moisture content do not change 275 significantly; however, the void ratio decreases and the components are denser, which 276 also increases the shear strength with the burial depth. 


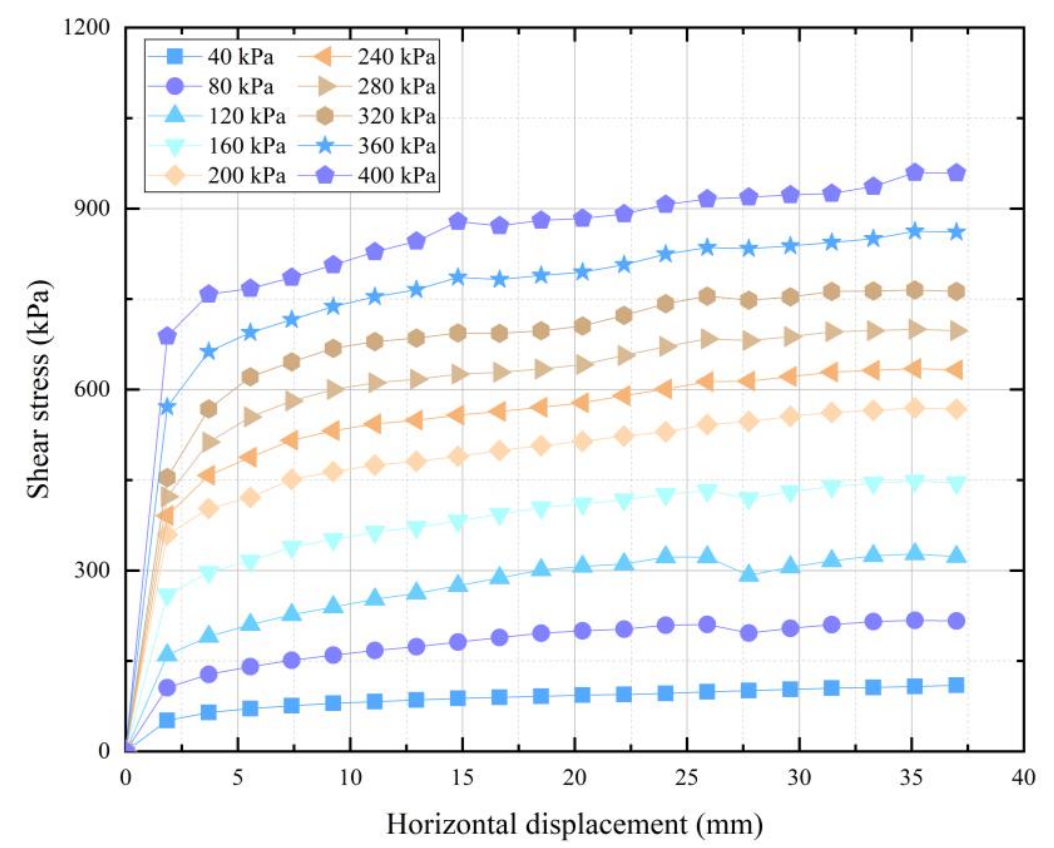

Figure 8 Shear stress-horizontal displacement graph (shearing rate is $5 \mathrm{~mm} / \mathrm{min}$ ).

281 Since MBT waste does not have a distinct shear strength peak, the shear stresses

282 when the shear strain reached 5, 10, 15, and $20 \%$ under each vertical pressure were 283 taken as the shear strength under this pressure. Taking the $5 \mathrm{~mm} / \mathrm{min}$ result as an 284 example, the relationship between shear strength and vertical pressure is plotted 285 (Figure 9). It can be seen from Figure 9 that with the increase in vertical pressure, the 286 shear stress of the sample also increases, indicating that the larger the pressure, the 287 denser the sample and larger the shear strength of the sample. Moreover, as the value 288 of shear horizontal displacement increases, the shear strength of MBT waste 289 increases; therefore, the value of horizontal displacement also affects the 
290 determination of material shear strength.

291

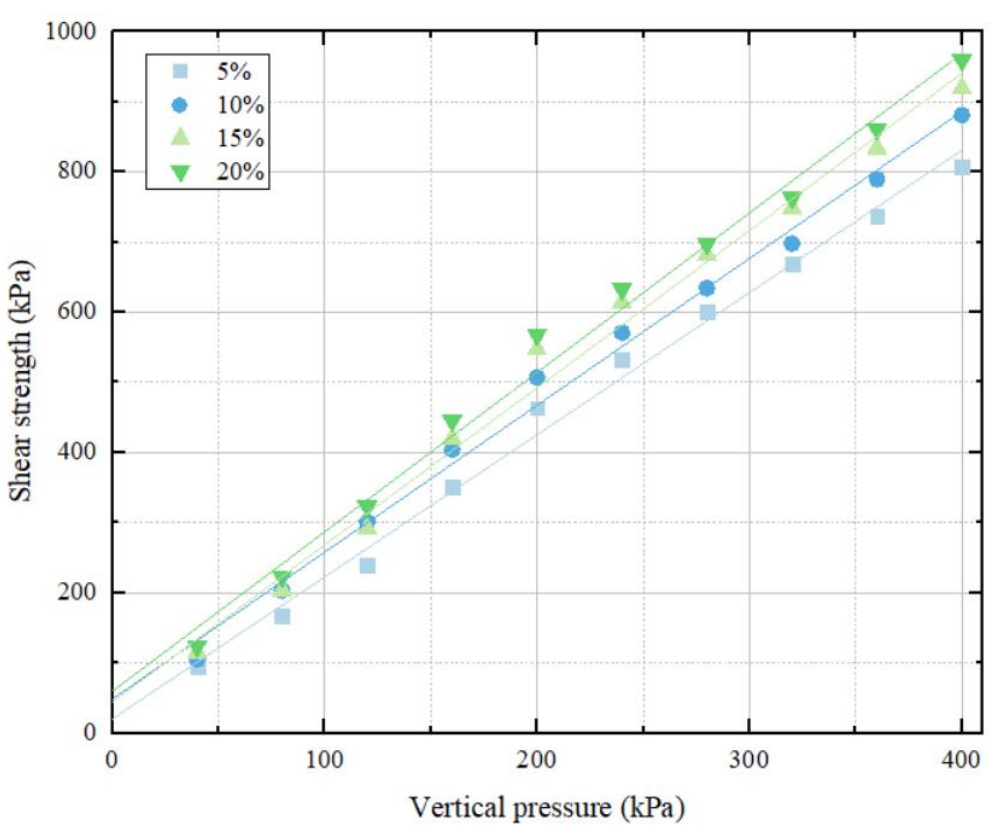

Figure 9 MBT waste shear strength envelope (shearing rate is $5 \mathrm{~mm} / \mathrm{min}$ ).

\subsection{Shear strength parameters in different shearing rate of MBT waste}

When the ratio of the shear horizontal displacement to the sample diameter under each vertical pressure reaches 10 and $20 \%$, the corresponding shear stress is taken as the shear strength under the pressure. As can be seen in Figure 10, as the shearing rate (logarithm) increases, the shear strength of the sample increases accordingly. This is similar to applying a rapid impact load to MBT waste. It takes a certain amount of energy to destroy MBT waste in a short time; therefore, the shear strength of MBT 
302 waste was improved. Additionally, owing to the high ratio of plastic to textile in the 303 material, there were more large-sized strip-shaped plastics and textiles participating in 304 the force. In addition, in the case of larger shearing displacement rates (10 and 20 $305 \mathrm{~mm} / \mathrm{min}$ ), it can be observed that the shear strength of the ratio of different shear 306 horizontal displacements to the sample diameter (10\% and 20\%) was not substantially 307 different. However, as the vertical pressure increased, the slope of the shear strength 308 line increased. This shows that choosing different shearing displacement rates and 309 shear displacements affects the shear strength. In addition, with a higher rate, although 310 the value of the shear displacement slightly effects the shear strength, different 311 vertical pressures have obvious changes in the shear strength of the material. 


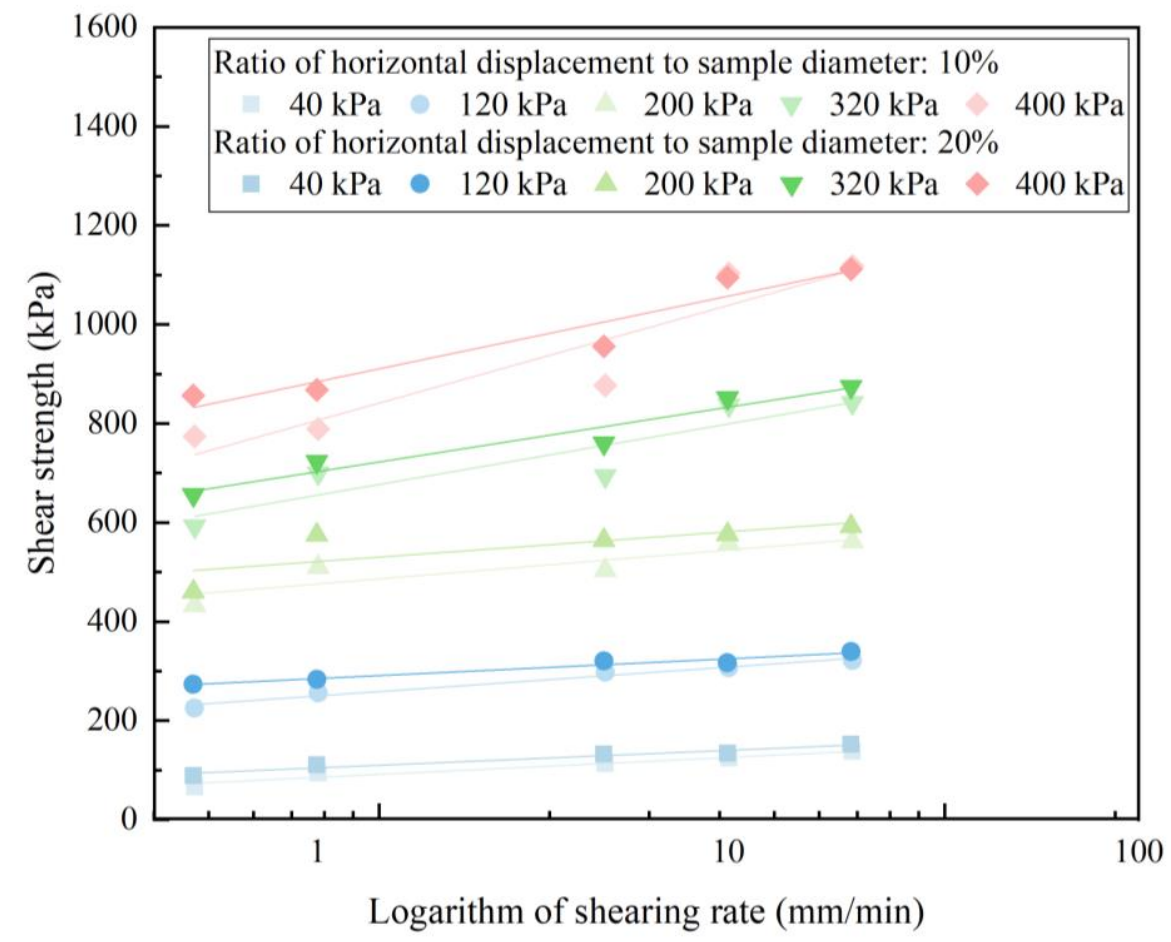

Figure 10 The relationship between shear strength and logarithm of shearing rate.

316 In order to better describe the correlation between shear strength and shearing

317 rate, a shearing rate sensitivity coefficient $\beta$ is introduced, formula (1).

$$
\beta=\frac{S_{i} / S_{0}}{\log \left(V_{i} / V_{o}\right)}
$$

319 where $S_{0}$ is the given initial shear stress $(\mathrm{kPa}), S_{i}$ is the shear stress $(\mathrm{kPa})$

320 corresponding to the shearing rate, $V_{0}$ is the given initial shearing rate $(\mathrm{mm} / \mathrm{min})$, and $321 V_{i}$ is the corresponding final shearing rate $(\mathrm{mm} / \mathrm{min})$.

Figure 11 shows that the shearing rate sensitivity coefficient can be fitted to a 
323 straight line. The absolute value of the slope of the straight line is 1.61 , and the 324 shearing rate sensitivity coefficient is between 0.64 and 2.66. The absolute value of 325 the slope of the line fitted by Zekkos et al. (2010) (test shearing rates are $0.1,1$, and 5 , 326 respectively) is 0.71 , and the rate sensitivity coefficient is between 0.5 and 1.0 . The 327 absolute value of the slope of the line fitted by Karimpour-Fard et al. (2013) (test 328 shearing rates are $0.8,8$, and 19 , respectively) is 0.55 , and the shearing rate sensitivity 329 coefficient is between 0.8 and 1.2. As the increment between shearing rates increases, 330 the sensitivity between shear strength and shearing rate decreases. The linear slope of 331 the MBT waste sample in this test is greater than that of the MSW sample, and the 332 shear strength and shearing rate sensitivity of MBT waste are strong.

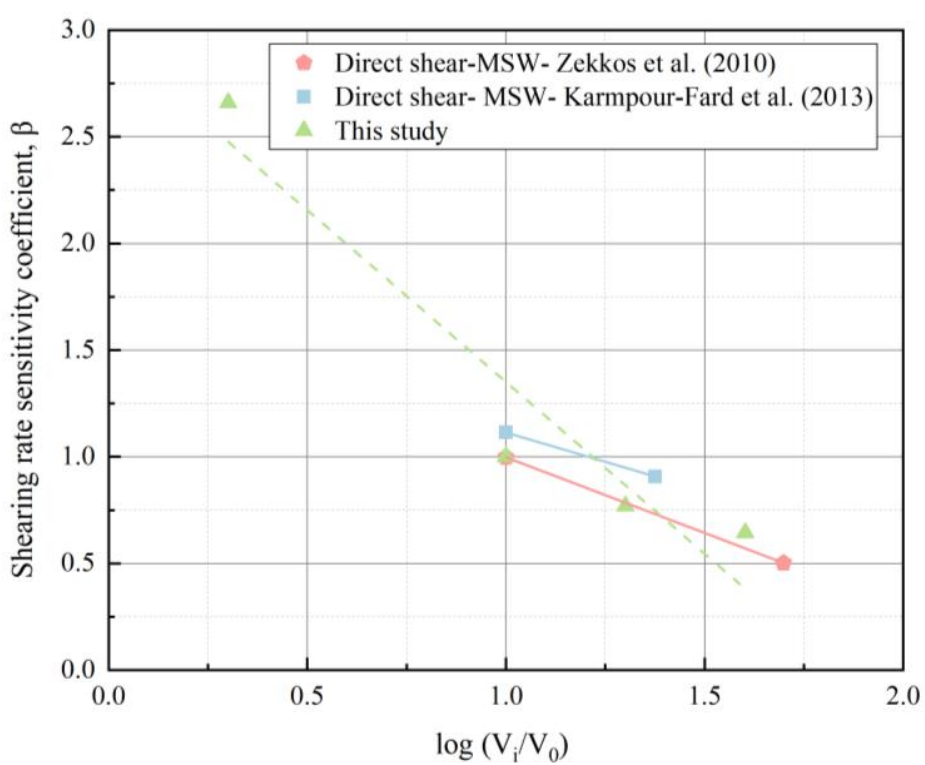


The shear strength parameters of MSW are calculated based on the Mohr-

338 Coulomb theory. The shear strength parameters of the MBT waste were obtained. The 339 relationship between the shear strength parameters $c$ and $\varphi$ of MBT waste with 340 different shearing rates and ratio of shear displacement to sample diameter are shown 341 in Figures 12 and 13. It can be seen from Figure 12 that the cohesion increases with 342 the increase in the ratio of shear displacement to the sample diameter and with the 343 increase in the shearing rate. When the ratio of shear displacement to sample diameter 344 was $20 \%$, the shearing rate increased from 0.25 to $20 \mathrm{~mm} / \mathrm{min}$, and the cohesive force 345 increased from 22.32 to $39.51 \mathrm{kPa}$. In particular, in the slow shearing rate $(0.25$ $346 \mathrm{~mm} / \mathrm{min}$ ) test at low ratio of shear displacement to sample diameter $(5 \%)$, the shear 347 strength of MBT waste is mainly caused by the friction angle, while the cohesion is 348 negligible. Figure 13 shows that the internal friction angle increases with the increase 349 of shearing rate, but has little relationship with the ratio of shear displacement to 350 sample diameter. When the ratio of shear displacement to sample diameter was $20 \%$, 351 the shearing rate increased from $0.25 \mathrm{~mm} / \mathrm{min}$ to $20 \mathrm{~mm} / \mathrm{min}$, and the internal friction 352 angle increased from $64.24^{\circ}$ to $68.52^{\circ}$, which is consistent with the results of Gao et 353 al. (2010). The reason for the increase in cohesion and internal friction angle is that 354 MBT waste becomes denser after consolidation and compression. The faster shearing 355 rate makes the MBT waste material swell and produces negative pressure. Meanwhile, 
356 band-shaped plastics and textiles are drawn to generate greater tensile stress, thereby 357 increasing the shear strength parameters.

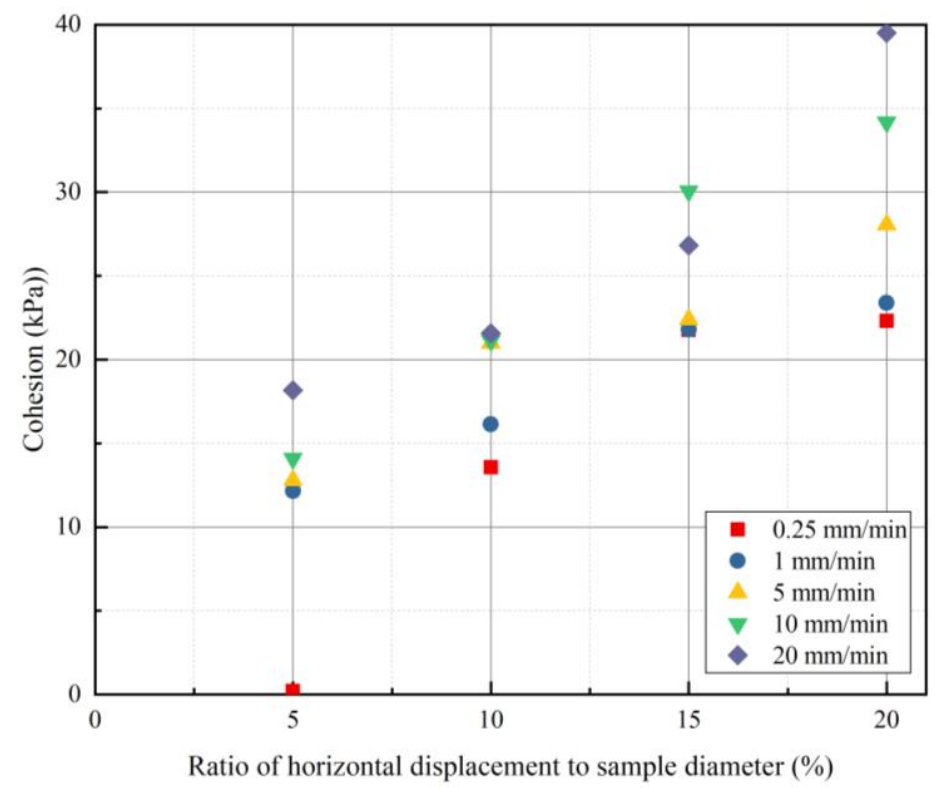

Figure 12 The relationship between cohesion and ratio of horizontal displacement to sample diameter. 


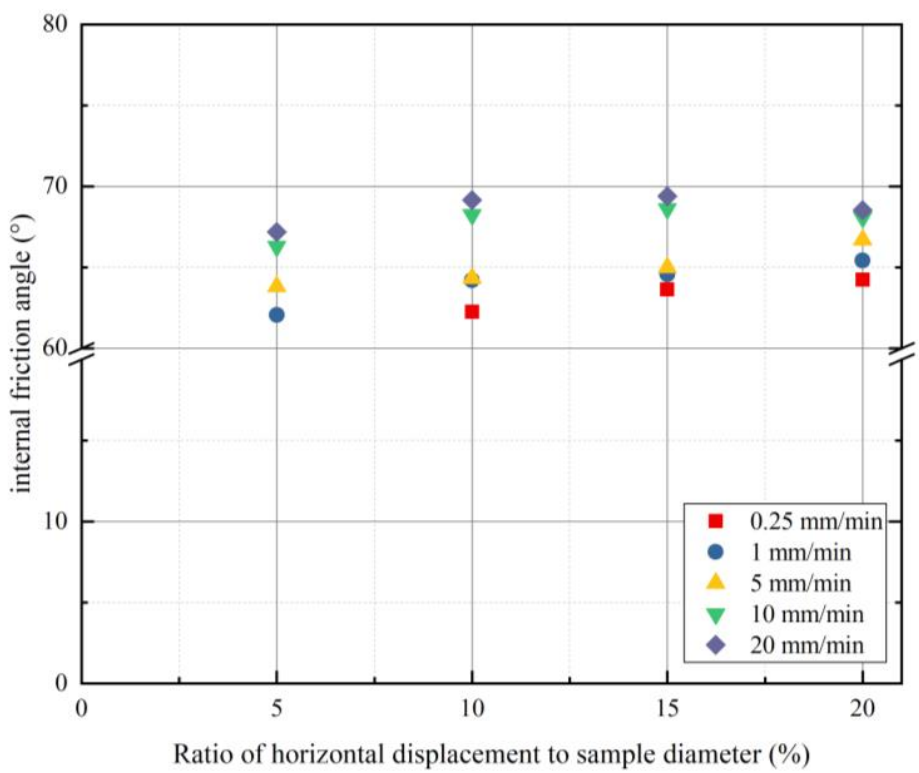

Figure 13 The relationship between internal friction angle and ratio of horizontal displacement to sample diameter.

\subsection{Shear strength prediction theoretical model}

366 The relationship among the shear strength, shearing rate, and vertical pressure of

367 MBT waste is shown in Figure 14. Figure 14 shows that the shear strength of MBT 368 waste increases with the increase in the shearing rate and vertical pressure. The 369 relationship between the shear strength of MBT waste and the shearing rate and

370 vertical pressure can be fitted to a non-linear surface. The fitting equation is shown in 371 equation (2), and the fitting correlation coefficient $\mathrm{R}^{2}$ is 0.98 , which shows a high degree of fit. 
376 is the shearing rate $(\mathrm{mm} / \mathrm{min})$, and the fitting coefficients $\mathrm{Z}_{0}, \mathrm{~B}, \mathrm{C}, \mathrm{D}$, and $\mathrm{E}$ are the 377 fitting correlation coefficients (Table 4).

378

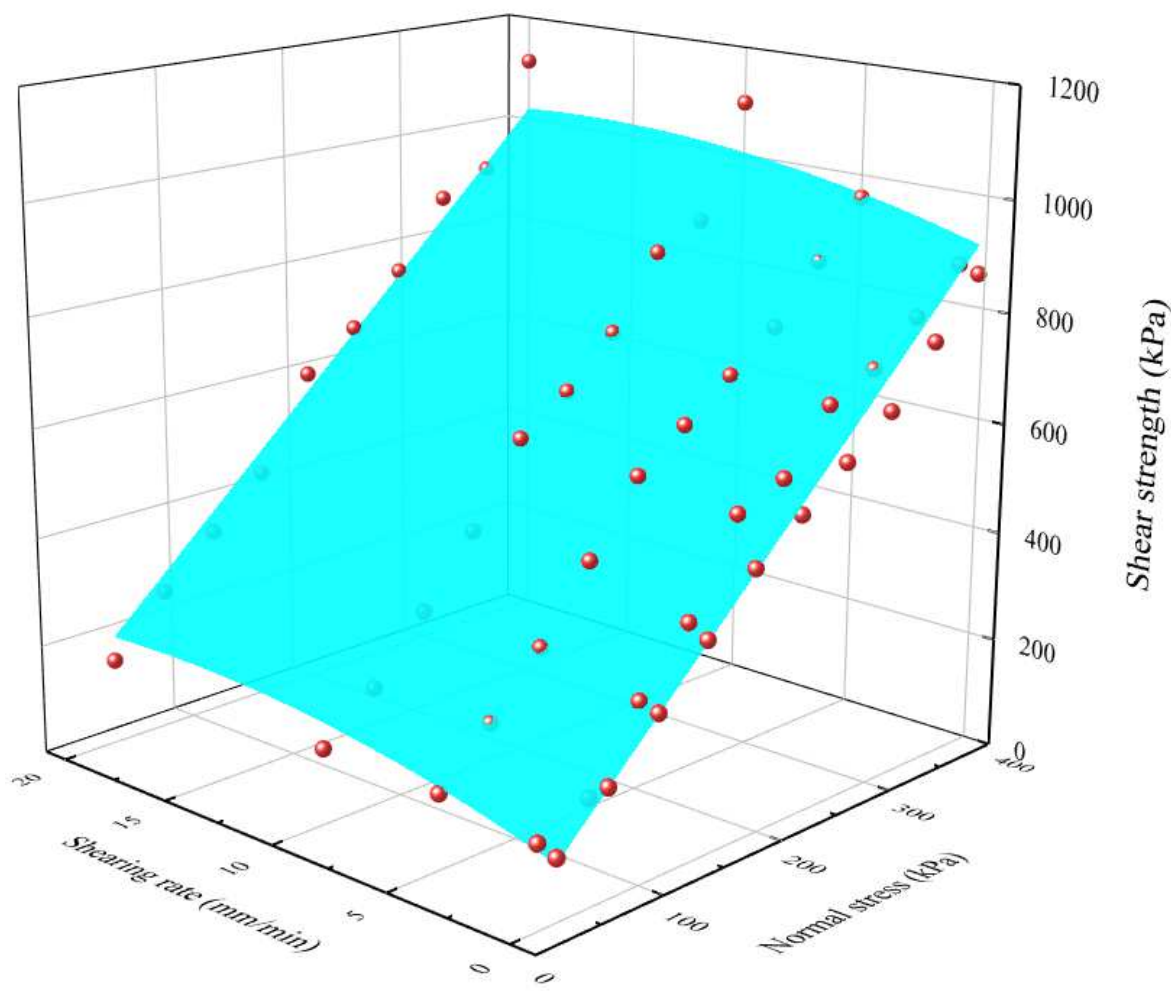




\begin{tabular}{ll}
\hline$Z_{0}$ & $-3.56 \pm 0$ \\
B & $2.26 \pm 0.03$ \\
C & $13.75 \pm 0.69$ \\
D & $4.82 \mathrm{E}-5 \pm 0$ \\
$\mathrm{E}$ & $-0.41 \pm 0$ \\
$\mathrm{R}^{2}$ & 0.98 \\
\hline
\end{tabular}

386 As shown in Figure 15, the relationship between the cohesion and the logarithm 387 of the shearing rate can be fitted to a straight line, and the average value of the fitting 388 correlation coefficient $\mathrm{R}^{2}$ is 0.91 . The degree of fit is relatively high, and the fitted 389 straight-line equation is shown in equation (3). As can be seen in Figure 16, the 390 relationship between the internal friction angle and the logarithm of the shearing rate 391 can be fitted to a straight line, and the average value of the fitting correlation 392 coefficient $R^{2}$ is 0.91 . The degree of fit is relatively high, and the fitted straight-line 393 equation is shown in equation (4).

$$
\begin{gathered}
\begin{cases}c=8.790 \log v+25.274 & (\varepsilon=10 \%) \\
c=4.562 \log v+16.495 & (\varepsilon=20 \%)\end{cases} \\
\begin{cases}\varphi=2.294 \log v+65.492 & (\varepsilon=10 \%) \\
\varphi=3.478 \log v+63.962 & (\varepsilon=20 \%)\end{cases}
\end{gathered}
$$

396 where $c$ is the cohesive force $(\mathrm{kPa})$ of the material, $v$ is the shearing rate $397(\mathrm{~mm} / \mathrm{min}), \varepsilon$ is the ratio of the horizontal displacement to the sample diameter, and $\varphi$ 
398 is the internal friction angle of the material $\left({ }^{\circ}\right)$.

399

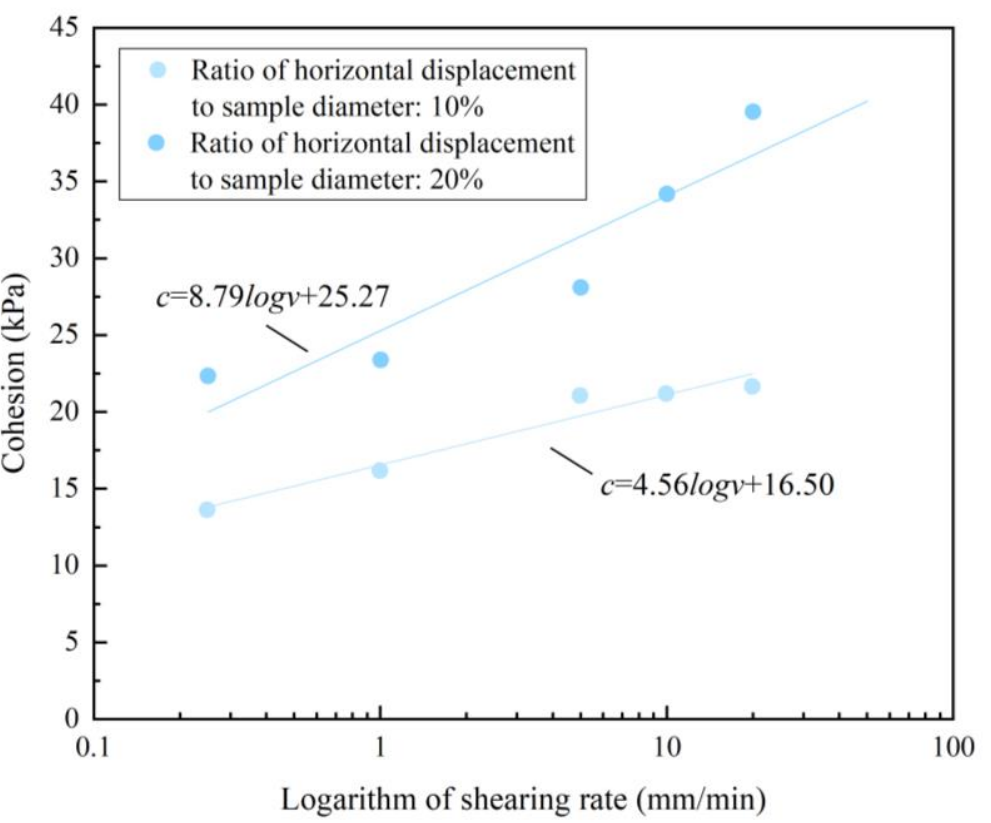

400

Figure 15 Relationship between cohesion and logarithm of shearing rate. 


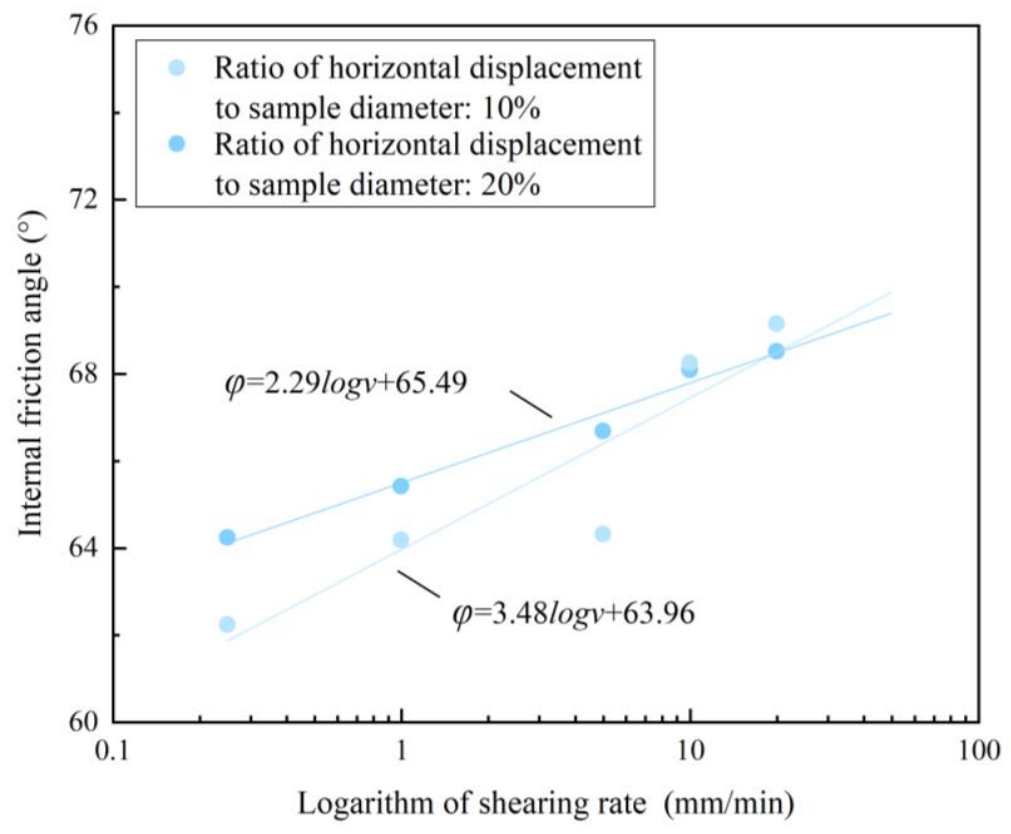

Figure 16 Relationship between internal friction angle and logarithm of shearing rate.

404

\section{Discussion}

\subsection{Sample moisture content}

407 We selected 18 references to compare the moisture content of HT landfill MBT

408 waste (Figure 17). It can be seen from Figure 17 that the moisture content is generally

409 distributed between 20-60\%, among which the moisture content of MBT waste is

410 between $18-40 \%$, and the moisture content of MSW is between $20-100 \%$. The

411 moisture content of MBT waste is generally lower than that of MSW, and the range of

412 variation is small. The main reason is that MBT technology removes most of the 413 organic matter in MSW and greatly reduces the moisture content of the material 
414 through air drying.

415

416 the heavy range of other MSW and MBT waste. By comparing the composition of 424 these wastes, it is observed that the percentage of plastic content in the MBT waste

Figure 17 Moisture content of each reference sample (green - MSW, blue - MBT waste).

\subsection{Sample unit weight}

The unit weight of the sample is shown in Figure 18. The unit weights of MBT waste, MSW, and HT-MBT waste are between $5.3-12.4 \mathrm{kN} / \mathrm{m}^{3}, 3.5-14.1 \mathrm{kN} / \mathrm{m}^{3}$, and 4-8 $\mathrm{kN} / \mathrm{m}^{3}$, respectively. Between them, The HT-MBT waste is generally smaller than

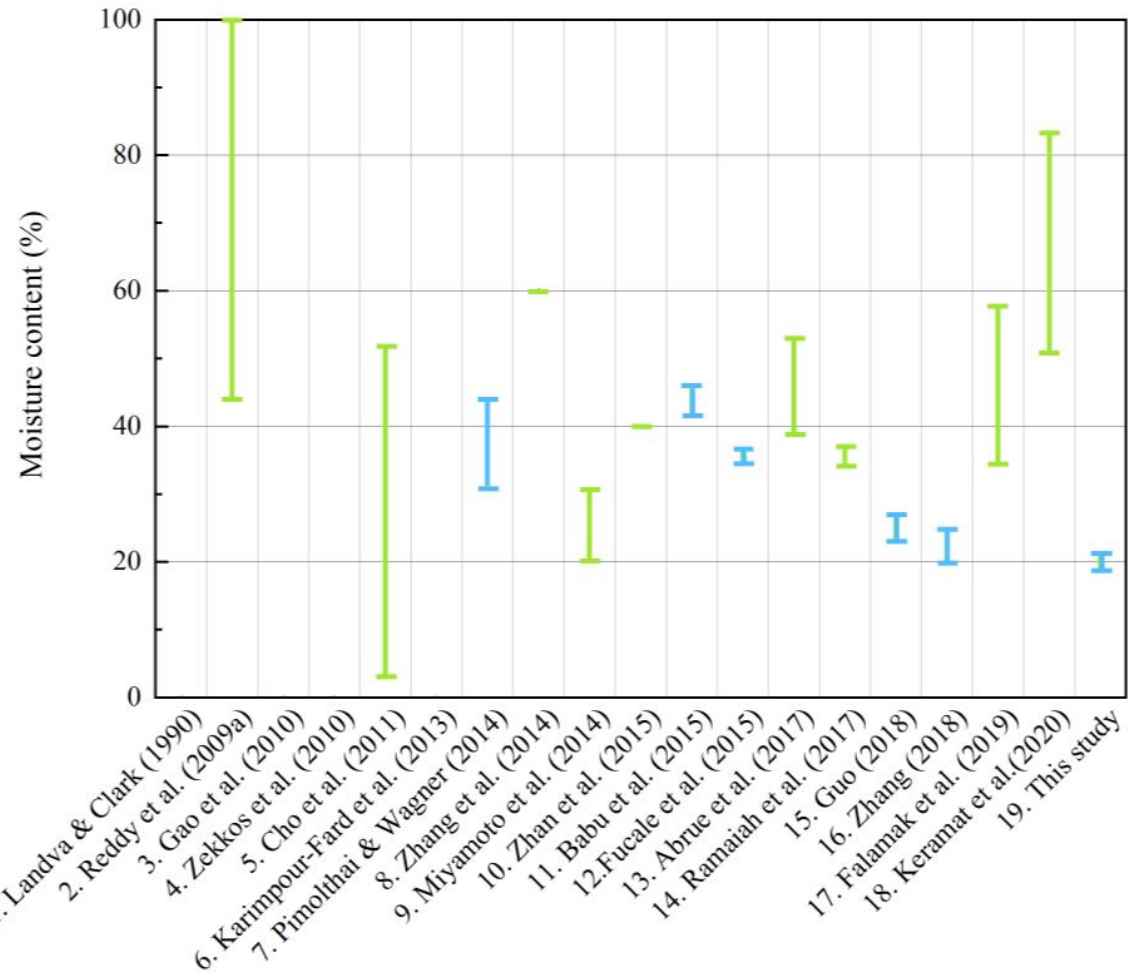


425 materials in HT landfill is higher than that of the above materials. On the one hand, 426 considering that most of the organic materials are eliminated, the unit weight of MBT 427 waste is lower. On the other hand, due to poor recycling awareness and different 428 consumption patterns, the increase in the percentage of low-weight and large-volume 429 plastics may also be the reason why the unit weight of MBT waste is relatively low.

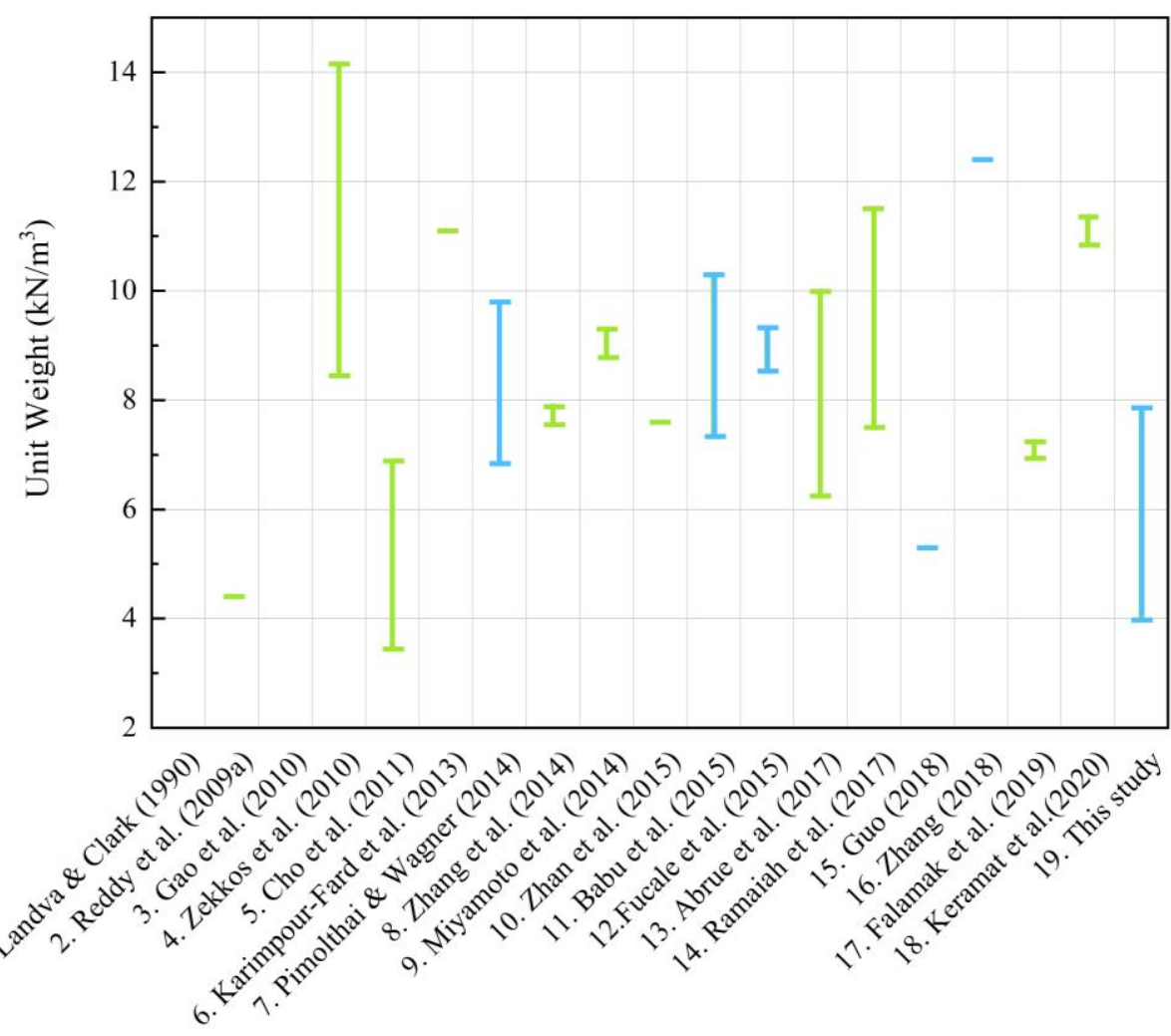




\subsection{Test parameters}

436 Table 5 lists the experimental parameters used in the references. Many scholars 437 have provided results of on-site (Miyamoto et al. 2014, Keramat et al. 2020), or 438 laboratory direct shearing of MSW or MBT waste. The largest sample size for 439 laboratory research reaches $860 \times 860 \times 620 \mathrm{~mm}$, the smallest is $60 \times 60 \times 30 \mathrm{~mm}$, 440 and the size of in site test samples can reach $1220 \times 1220 \times 750 \mathrm{~mm}$. Further, the DS 441 test device is divided into square and round shapes; the test shear box used in this 442 study was a relatively large round shear box. The range of vertical pressure applied 443 was $2-774 \mathrm{kPa}$, and the vertical pressure range for most of the tests was $50-200 \mathrm{kPa}$. 444 The duration of the pressure application is generally $\sim 1440 \mathrm{~min}$. Most of the literature 445 research content includes material composition, moisture content, buried depth, 446 severity, age, fibre orientation, void ratio, particle size, top overburden pressure, upper 447 earth pressure, and self-weight stress on MSW/MBT shear impact of intensity. Only 448 Zekkos et al. (2010) and Karimpour-Fard et al. (2013) studied the effect of multiple 449 shearing rates on shear strength. Zekkos et al. (2010) studied the effects of different 450 components, unit weights, and shearing rates on the shear strength of MSW. The 451 shearing rates were $0.1,1$, and $5 \mathrm{~mm} / \mathrm{min}$, and the vertical pressures were 2,50 , and 452150,370 , and $700 \mathrm{kPa}$ and held for $1440 \mathrm{~min}$. The test results show that the greater 453 the depth in the landfill, the greater the reduction of the internal friction angle, and 454 that the shear strength is likely to correspond to the weakest direction of the shear 
455 plane. Karimpour-Fard et al. (2013) studied the influence of fibre content, fibre 456 orientation, age, and shearing rate on MSW, applying 20, 50, 100, and $200 \mathrm{kPa}$ 457 vertical pressures and maintaining them for $1440 \mathrm{~min}$. The shearing rate was set to $4580.8,8$, and $19 \mathrm{~mm} / \mathrm{min}$. The results show that as the shearing rate increased, as did the 459 shear strength of MSW. When the horizontal displacement was $1.5,3$, and $4.5 \mathrm{~cm}$, the 460 shear strength of MSW increased to $27 \%, 22 \%$, and $16 \%$, respectively. The sensitivity 461 coefficient is up to 0.33 . This study investigates the effect of shearing rate on the 462 strength of MBT waste materials, and the set rate covers the above-mentioned rates. A 463 vertical pressure of $40-400 \mathrm{kPa}$ was applied to simulate the self-weight stress at a 464 landfill depth of 10-100 m.

465

466 Table 5 Reference test parameters.

\begin{tabular}{|c|c|c|c|c|c|}
\hline Number & Reference & Sample type & $\begin{array}{l}\text { Vertical stress } \\
\text { duration (min) }\end{array}$ & $\begin{array}{l}\text { Testing method and } \\
\text { sample size }(\mathrm{mm})\end{array}$ & $\begin{array}{l}\text { Displacement or strain at the shearing } \\
\text { resistance considered and vertical } \\
\text { pressure }(\mathrm{kPa})\end{array}$ \\
\hline 1 & Landva \& Clark (1990) & MSW & NA & L-DS, $434 \times 287$ & PS, 30.3-565 \\
\hline 2 & Reedy et al. (2009) & MSW & NA & L-DS, 70(D) & $\mathrm{PD}(15 \%), 176-774$ \\
\hline 3 & Gao et al. (2010) & MSW & 120 & L-DS, $300 \times 300 \times 150$ & $\mathrm{PD}(6.7 \%$ and $10 \%), 50-300$ \\
\hline 4 & Zekkos et al. (2010) & MSW & 1440 & L-DS, $300 \times 300 \times 180$ & $\mathrm{PD}(55 \mathrm{~mm}), 2-700$ \\
\hline 5 & Cho et al. (2011) & MSW & $240-1800$ & $\begin{array}{l}\text { L-DS, } 100(\mathrm{D}) \\
860 \times 860 \times 620\end{array}$ & $\begin{array}{l}\mathrm{PD}(18 \%), 48-290 \\
\mathrm{PD}(30 \%), 96-287\end{array}$ \\
\hline 6 & $\begin{array}{l}\text { Karimpour-Fard et al. } \\
\text { (2013) }\end{array}$ & MSW & 1440 & L-DS, $300 \times 300 \times 150$ & $\mathrm{PD}(5,10$ and $15 \%), 20-200$ \\
\hline
\end{tabular}




\begin{tabular}{|c|c|c|c|c|c|}
\hline 7 & $\begin{array}{l}\text { Pimolthai \& Wagner } \\
\text { (2014) }\end{array}$ & MBT-MSW & NA & L-DS, 94(D) & PS, 20-100 \\
\hline 8 & Zhang et al. (2014) & MSW & $0-1440$ & L-DS, $150(\mathrm{D})$ & $\mathrm{PD}(20 \%), 25-200$ \\
\hline 9 & Miyamoto et al. (2014) & MSW & 10 & I-DS, $300 \times 150$ & $\mathrm{PD}(40 \mathrm{~mm}), 8.2-13.6$ \\
\hline 10 & Zhan et al. (2015) & MSW & $30-740$ & L-DS, 618(D) & $\mathrm{PD}(10 \%), 12.5-100$ \\
\hline 11 & Babu et al. (2015) & MBT-MSW & NA & L-DS, $60 \times 60 \times 30$ & $\mathrm{PD}(20 \%), 50-150$ \\
\hline 12 & Fucale et al. (2015) & MBT-MSW & 4320 & L-DS, $100 \times 100 \times 150$ & PD (20\%), $100-300$ \\
\hline 13 & Abrue et al. (2017) & MSW & 250 & L-DS, $500 \times 500 \times 500$ & $\mathrm{PD}(20 \%), 50-250$ \\
\hline 14 & Ramaiah et al. (2017) & MSW & 700 & L-DS, $305 \times 305 \times 203$ & $\mathrm{PD}(55 \mathrm{~mm}), 25-200$ \\
\hline 15 & Guo (2018) & MBT-MSW & 1440 & L-DS, $180(D)$ & $\mathrm{PD}(10 \%, 15 \%), 50-200$ \\
\hline 16 & Zhang (2018) & MBT-MSW & 1440 & L-DS, 200(D) & $\mathrm{PD}(20 \%), 12.5-200$ \\
\hline 17 & Falamak et al. (2019) & MSW & 1440 & L-DS, $300 \times 300 \times 165$ & PS, 50-200 \\
\hline 18 & Keramat et al. (2020) & MSW & NA & I-DS, $1220 \times 1220 \times 750$ & $\mathrm{PD}(4 \%), 6.7-22.2$ \\
\hline 19 & This study & MBT-MSW & 1440 & L-DS, $185(\mathrm{D})$ & $\mathrm{PD}(5 \%, 10 \%, 15 \%$ and $20 \%), 40-400$ \\
\hline
\end{tabular}

467 L laboratory tests, I in-site tests, DS direct shear, PS peak stress, PD peak displacement, NA not 468 available.

\subsection{Shear strength parameters}

471 We collected references with a time span of up to $30 \mathrm{y}$ (1990-2020), extracted

472 shear strength parameters (data with similar strain values) obtained at various shearing 473 rates in the literature. The influence of shearing rate on the shear strength parameters 474 of materials was compared (Figure 19).

475 Figure 19 shows that as the shearing rate increases, the shear strength parameters $476 c$ and $\varphi$ of MSW and MBT waste also increase. The variation range of MSW cohesion 477 is generally between $0-46 \mathrm{kPa}$, and cohesion range of MBT waste is concentrated 
478 between 5.4-39.5 $\mathrm{kPa}$ (some data points with larger increases are excluded), and the 479 range of MSW cohesion larger than MBT waste. The MSW internal friction angle 480 range was $7-50.6^{\circ}$, and the MBT waste internal friction angle range was $17.2-48.1^{\circ}$; 481 most fluctuate around $30^{\circ}$. The internal friction angle range of this study was 59.92$48268.52^{\circ}$, which is generally greater than the conclusions of other literature. The main 483 reasons for the difference in shear strength parameters of MSW and MBT waste are 484 the different components of the materials and different shearing rates. Different 485 components and different shearing rates will show different physical and mechanical 486 properties. In addition, MBT pre-treatment technology has only been studied by 487 scholars in some countries, which also partly explains the small range of test results. 

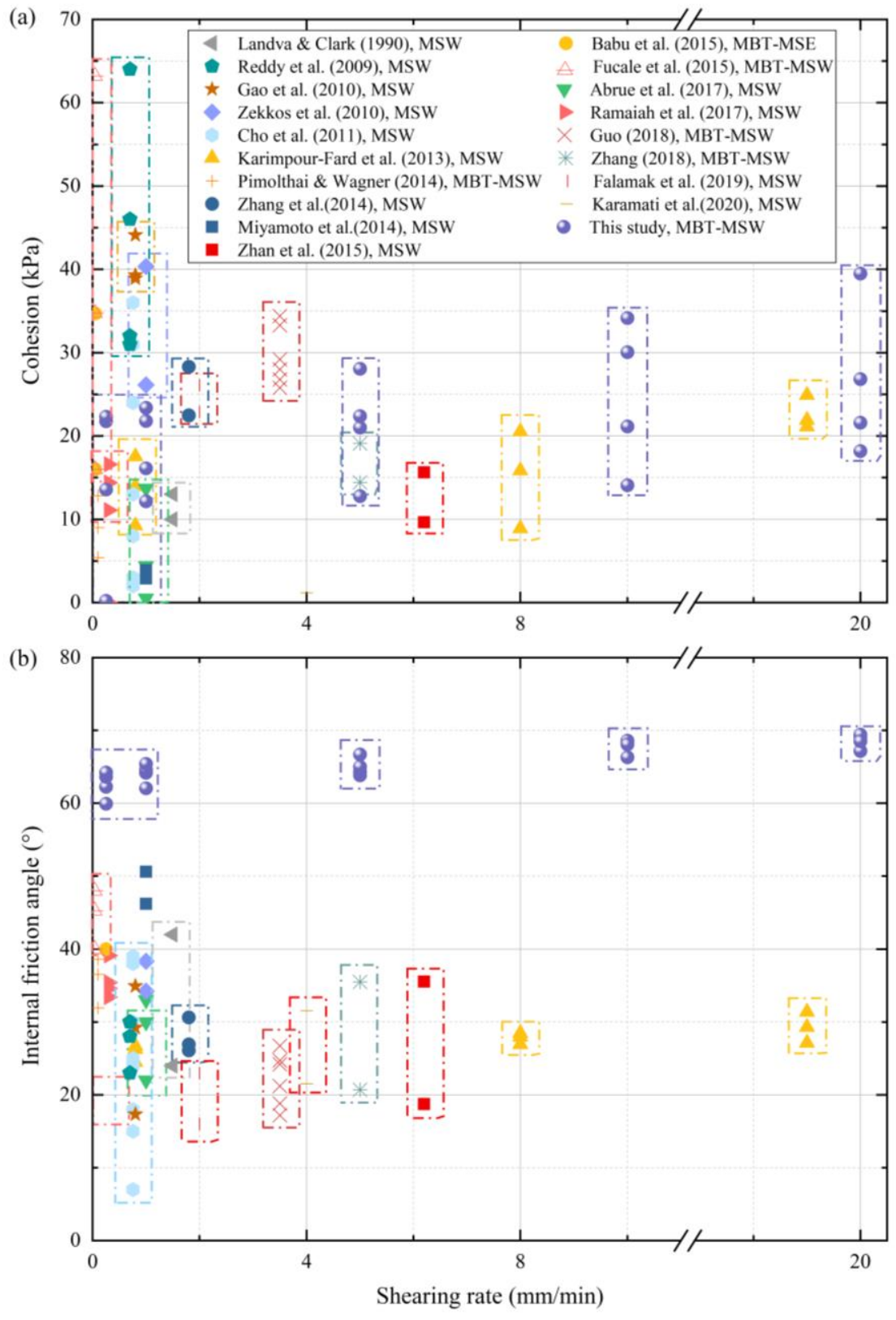

490 Figure 19 Comparison of shear strength parameters (a) the relationship between cohesion and 491 shearing rate, (b) the relationship between internal friction angle and shearing rate. 


\section{Conclusion}

To supplement the relationship between MBT waste in shearing rate, landfill depth and shear strength. In this study, the direct shear test was used to test the MBT waste, and the experimental phenomenon that the shear strength increases with shearing rate increases. Furthermore, a theoretical model of shear strength prediction was established, and the range of shear strength parameters was obtained. The

499 findings of this work provide basic data and strength models for the design, instability 500 and damage prediction of MBT landfills. The specific conclusions are as follows:

(1) MBT waste was mainly composed of paper, plastic, rubber, textile, wood, stone, ceramics, glass, metal, fine-grained soil, and other visually indistinguishable 503 materials. Among them, plastic and rubber are the most important in MBT waste 504 ingredients (23.3\% dry mass). The measured moisture content was $20 \%$, which is 505 significantly lower than that of MSW. The measured specific gravity was 1.53 .

506 (2) With an increase in the horizontal displacement of MBT waste, the shear 507 stress of the sample does not exhibit an obvious peak, indicating a displacement 508 hardening phenomenon. MBT waste complies with the Mohr-Coulomb theory. As the 509 value of shear horizontal displacement increases, the shear strength of MBT waste 510 increases.

511 (3) A DS test instrument was used to study the influence of different shearing 512 rates on the shear strength of MBT waste. The test results show that as the shearing 
513 rate increased, the shear strength of MBT waste increased. The sensitivity coefficient 514 between the shearing rate and shear strength of MBT waste was 0.64-2.66.

515 (4) A DS test instrument was used to simulate the influence of different landfill 516 depths on the shear strength of MBT waste. The test results show that the shear 517 strength increased with an increase in the buried depth.

518 (5) We established an MBT waste shear strength prediction model considering 519 the effects of shearing rate and normal stress simultaneously. This model can simulate 520 and predict the changes in MBT waste shear strength with shearing rate and vertical 521 pressure. The model was fitted into a nonlinear smooth surface in a rectangular 522 coordinate system with a fitting coefficient of 0.98 .

523 (6) The relationship between cohesion $c$ and the logarithm of the shearing rate 524 can be fitted to a straight line, with an average fitting coefficient of 0.91 . The law 525 conforms to the logarithmic model, and the expression of the logarithmic model is 526 established. The cohesive force increased with the increase in the shearing rate and 527 with the increase in horizontal displacement.

528 (7) The relationship between the internal friction angle $\varphi$ and logarithm of the 529 shearing rate, $\log v$, could be fitted to a straight line, with an average fitting coefficient 530 of 0.91 . The law conformed to the logarithmic model, and the expression of the 531 logarithmic model was established. In contrast to the cohesive force, the slope of the 532 straight line with $\varepsilon=20 \%$ was less than $\varepsilon=10 \%$. This is because under large 
533 horizontal shear displacement, some of the reinforced materials are broken and 534 damaged, and the effect of the reinforcement is weakened.

535 (8) The cohesion $c$ of MBT waste was in the range of $22.32-39.51 \mathrm{kPa}$, and the 536 internal friction angle $\varphi$ was in the range of $64.24^{\circ}-68.52^{\circ}$.

538 Ethics approval and consent to participate

$539 \quad$ Not applicable.

540 Consent for publication

$541 \quad$ Not applicable.

542 Availability of data and materials

543 The datasets used and/or analysed during the current study are available from the

544 corresponding author on reasonable request.

545 Competing interests

546 The authors declare that they have no competing interests.

\section{$547 \quad$ Funding}

548 This research was funded by the National Natural Science Foundation of China

549 (Contract Nos. 51978625 and 51678532) and supported by Zhejiang Provincial

550 Natural Science Foundation of China under Grant No. LZ21E080003.

\section{Authors' contribution}


Jiahe Zhang conducted the direct shear test on Hangzhou Tianziling MBT waste,

553 and analyzed and interpreted the influence of shearing rate on the shear strength of

554 MBT waste. Qiaona Wang, Min Wang and Chenyu Nie conducted the direct shear test 555 on Hangzhou Tianziling MBT waste, Zhenyiing Zhang analyzed the test data, and 556 reviews and revises the full text. All authors read and approved the final manuscript.

\section{Acknowledgements}

559 Thanks for the help of the Hangzhou Environmental Group.

\section{References}

Abreu AES and Vilar OM (2017) Influence of composition and degradation on

563 the shear strength of municipal solid waste. Waste Management 68: 263-274.

564 Archer E, Baddeley A, Klein A, Schwager J, Whiting, K (2005) Mechanical-

565 Biological Treatment: A guide for decision makers processes, policies, markets.

566 Juniper Consultancy Services Ltd, Uley, England., pp. 650.

567 Babu GLS, Lakshmikanthan P, Santhosh LG (2015) Shear strength characteristics 568 of mechanically biologically treated municipal solid waste (MBT-MSW) from 569 Bangalore. Waste Management 39(5): 63-70.

570 Bareither CA, Benson CH, Edil TB (2012) Effects of Waste Composition and

571 Decomposition on the Shear Strength of Municipal Solid Waste. Journal of 
Geotechnical and Geoenvironmental Engineering 138(10): 1161-1174.

Bhandari AR and Powrie W (2013) Behavior of an MBT waste in monotonic triaxial shear tests. Waste Management 33: 881-891.

Bray JD, Zekkos D, Kavazanjian E, Athanasopoulos GA, Riemer MF (2009) Shear strength of municipal solid waste. In: International Symposium on Waste Mechanics 1356: 709-722.

Cho YM, Ko JH, Chi L, Townsend TG (2011) Food waste impact on municipal solid waste angle of internal friction. Waste Management 31: 26-32.

Eskandari M, Homaee M, Falamaki A (2016) Landfill site selection for municipal solid wastes in mountainous areas with landslide susceptibility. Environmental Science and Pollution Research 23(12):12423-12434.

Falamaki A, Ghareh S, Homaee M, Hamtaeipour Shirazifard A, Abedpour S, Kiani S, Mousavi N, Rezaei M, Motlagh MT, Nouri A (2019) Laboratory Shear Strength Measurements of Municipal Solid Waste at Room and Simulated In Situ Landfill Temperature, Barmshoor Landfill, Iran. International Journal of Environmental Science and Technology 18: 185-197.

Falamaki A, Ghareh S, Homaee M, Shirazifard AH, Abedpour S, Kiani S, et al. (2019) laboratory shear strength measurements of municipal solid waste at room and simulated in situ landfill temperature, Barmshoor landfill, Iran. International Journal of Civil Engineering 18: 185-197. 
Fard MK, Shariatmadari N, Keramati M, Kalarijani HJ (2015) An experimental 593 investigation on the mechanical behavior of MSW. International Journal of Civil 594 Engineering 12(4): 292-303.

Fei XH and Zekkos D (2017) Comparison of direct shear and simple shear 596 responses of municipal solid waste in USA. Journal of Environmental Geotechnics $597 \quad 5(3): 158-167$.

598 Feng SJ, Gao KW, Chen YX, Li Y, Zhang LM, Chen HX (2017) Geotechnical 599 properties of municipal solid waste at Laogang Landfill, China. Waste Management $600 \quad 63: 354-365$.

601 Fernando VI and Sudarshana CK (2011) Shear strength characteristics of 602 mechanically biologically treated (MBT) waste. University of Southampton.

603 Frenando S, Powrie W, Wastson G, Richards DJ (2009) The Impact of the 604 reinforce content on the shear strength of mechanically biologically treated waste. In: 605 Third International Workshop "Hydro-Physico-Mechanics of Landfills" 3: 10-13.

606 Fucale S, Juca JFT, Muennich K (2015) The mechanical behavior of MBT waste. 607 Electronic Journal of Geotechnical Engineering 20(13): 5927-5931.

608 Fucale SP (2005) Influência dps componentes de reforço na resistência de 609 resíduos sólidos urbanos. Federal University of Pernambuco, Brazil, 219 p.

610 Gao W, Chen Y, Zhan L, Bian X (2015) Engineering properties for high kitchen 611 waste content municipal solid waste. Journal of Rock Mechanics \& Geotechnical 
Engineering (6):646-658.

613 Gao W, Tu F, Xiao C, Ke Q, Xie Z (2010) Experimental study on repeated direct 614 shear of municipal solid waste from different depth of landfill. Chinese Journal of 615 Environmental Engineering 4(5): 1171-1176.

616 Guerrero LA, Maas G, Hogland W (2013) Solid waste management challenges for 617 cities in developing countries. Waste Management 33(1):220-232.

618 Guo WQ (2018) Laboratory study on the strength characteristics of MBT waste. 619 Zhejiang Sci-tech University (in Chinese).

620 Jones DRV \& Dixon N (2015) Landfill lining stability and integrity: the role of 621 waste settlement. Geotextiles \& Geomembranes 23(1): 27-53.

622 Jones DRV, Taylor DP, Dixon N (1997) Shear strength of waste and its use in 623 landfill stability. In: Yong, R.N., Thomas, H.R. (Eds.), Proceedings Geoenvironmental 624 Engineering Conference. Thomas Telford, pp. 343-350. Karimpour-Fard M (2018) Rehabilitation of Saravan dumpsite in Rasht, Iran: 626 geotechnical characterization of municipal solid waste. International Journal of 627 Environmental Science \& Technology 16: 4419-4436.

628 Karimpour-Fard M (2018) Rehabilitation of Saravan dumpsite in Rasht, Iran: 629 geotechnical characterization of municipal solid waste. International Journal of 630 Environmental Science \& Technology 16(8): 4419-4436.

631 Karimpour-Fard M, Machado SL, Shariatmadari N, Noorzad A (2010) A 
632 laboratory study on the MSW mechanical behavior in triaxial apparatus. Waste 633 Management 8(31): 1807-1819.

634 Karimpour-Fard M, Shariatmadari N, Keramati M, Jafari-Kalarijani H (2013) An 635 experimental investigation on the mechanical behavior of MSW. International 636 Journal of Civil Engineering 12(4):292-303.

637 Kavazanjian N, Matascovic R, Bonaparte GR, Schmertmazin E (1995) Evaluation 638 of evaluation of MSW properties for seismic analysis. Geoenviron. 2000, Geotech. 639 Special Publ. ASCE. 46, 1126-1141.

640 Keramati M, Shahedifar M, Aminfar MH, Alagipuor H (2020) Evaluation the 641 Shear Strength Behavior of aged MSW using Large Scale In Situ Direct Shear Test, a 642 case of Tabriz Landfill. International Journal of Civil Engineering 18: 717-733.

643 Kuehle-Weidemeier M (2004) Landfilling of mechanically-biologically pretreated 644 municipal solid waste. International Symposium Waste Management, Zagreb, VIII.

645 Landva AO and Clark JI (1990) Geotechnics of waste fill. Geotechnics of waste 646 fills-theory and practice, ASTM STP 1070. In: Landva, A., Knowles, D. (Eds.), 647 American Society for Testing and Materials. Philadelphia, Pennsylvania, pp 86-103. 648 Machado SL, Carvalho FM, Vilar OM (2002) Constitutive model for municipal 649 solid waste. Journal of Geotechnical and Geoenvironmental Engineering, 128 (11): $650 \quad 940-951$.

651 Mahler CF and Neto ADL (2006) Effect of fibre on shear strength of residue from 
652 mechanical biological pretreatment of waste. International Journal of Environment \& 653 Waste Management 1(1): 85-93.

654 Manassero M, Van Impe WF, Bouazza A (1996) Waste disposal and containment. 655 Proc. 2nd Int. Cong. Environ. Geotech. Osaka, Japan 3, 1425-1474.

656 Miyamoto S, Yasufuku N, Ishikura R, Omine K, Yamawaki A (2014) In-situ 657 shearing response and shear strength of various solid waste ground focused on fibrous 658 materials composition. In: TC105 ISSMGE International Symposium on 659 Geomechanics from Micro to Macro, 1357-1362.

660 Petrović I and Bauer E (2011) A simple hypoplastic model for simulating the 661 mechanical behaviour of MBT waste. Computational Geomechanics, COMGEO II-In 662 Proceedings of the 2nd International Symposium on Computational Geomechanics 663 pp: 337-346.

664 Pimolthai P and Wagner JF (2014) Soil mechanical properties of MBT waste 665 from Luxembourg, Germany and Thailand. Songklanakarin Journal of Science and 666 Technology 36(6):701-709.

667 Ramaiah BJ, Ramana GV, Datta M (2017) Mechanical characterization of 668 municipal solid waste from two waste dumps at Delhi, India. Waste Management 68: $669 \quad 275-291$.

670 Reddy KR, Gangathulasi J, Parakalla NS, HettiarachchiH, Bogner JE, Lagier T 671 (2009b) Compressibility and shear strength of municipal solid waste under short-term 
672 leachate recirculation operations. Waste Management 27(6): 578-587.

673 Reddy KR, Hettiarachchi H, Parakalla NS, Gangathulasi J, Bogner JE (2009a)

674 Geotechnical properties of fresh municipal solid waste at Orchard Hills Landfill,

675 USA. Waste Management 29(2):952-959.

676 Singh S, Murphy B (1990) Evaluation of the stability of sanitary landfills. 677 Geotech. Waste Fills - Theory Pract. ASTM STP 1070: 240-258.

678 Stark, T.D., Sarihan, N.H., Li, G (2009) Shear strength of municipal solid waste 679 for stability analyses. Environmental Geology 57, 1911-1923.

680 Tatsuoka F, Di Benedetto H, Enomoto T, Kawabe S, Kongkitkul W (2008)

681 Various viscosity types of geomaterials in shear and their mathematical expression, 682 Soil and Foundation 1(48): 41-60.

683 Zekkos D and Fei XH (2016) Constant load and constant volume response of 684 municipal solid waste in simple shear. Waste Management 63(5): 380-392.

685 Zekkos D, Athanasopoulos GA, Bray JD, Grizi A, Theodoratos A (2010) Large686 scale direct shear testing of municipal solid waste. Waste Management 30: 1544-1555. 687 Zekkos DP (2005) Evaluation of static and dynamic properties of municipal solid 688 waste. A dissertation submitted in partial satisfaction of the requirements for the 689 degree of Doctor of Philosophy in Geotechnical Engineering, University of 690 California, Berekeley.

691 Zhan TLT, Chen YM, Ling WA (2008) Shear strength characterization of 
692 municipal solid waste at the Suzhou landfill, China. Engineering Geology 97(3-4): $97-$ 693111.

694 Zhan XD, Yan LJ, Wu DZ, Zhang ZY (2015) Ultra-large direct shear test for 695 shear strength properties of artificial municipal solid waste. Journal of Engineering 696 Geology 23(5): 930-936.

697 Zhang Y (2018c) Research on municipal solid waste output forecast and MBT 698 volume reduction technology. Zhejiang Sci-tech University (in Chinese).

699 Zhang ZY, Yan LJ, Wu DZ (2014) Experimental study of compression and direct 700 shear combined test. Rock and Soil Mechanics 35(11): 3049-3055.

701 Zhang ZY, Yan LJ, Wu DZ, Zhang LF, Fu J, Hu YJ (2015) Experimental study 702 on shear strength parameters of fresh municipal solid waste. Chinese Journal of 703 Geotechnical Engineering 37(3): 432-439.

704 Zhang ZY, Zhang YX, Wang YF, Xu H, Guo WQ, Wu DZ, Fang YH (2018a) 705 Physical and Mechanical Characteristics of MBT Waste in China. In: Farid A., Chen 706 H. (eds) Proceedings of GeoShanghai 2018 International Conference: 707 Geoenvironment and Geohazard. GSIC 2018. Springer, Singapore. 708 https://doi.org/10.1007/978-981-13-0128-5_46. 


\section{Figures}

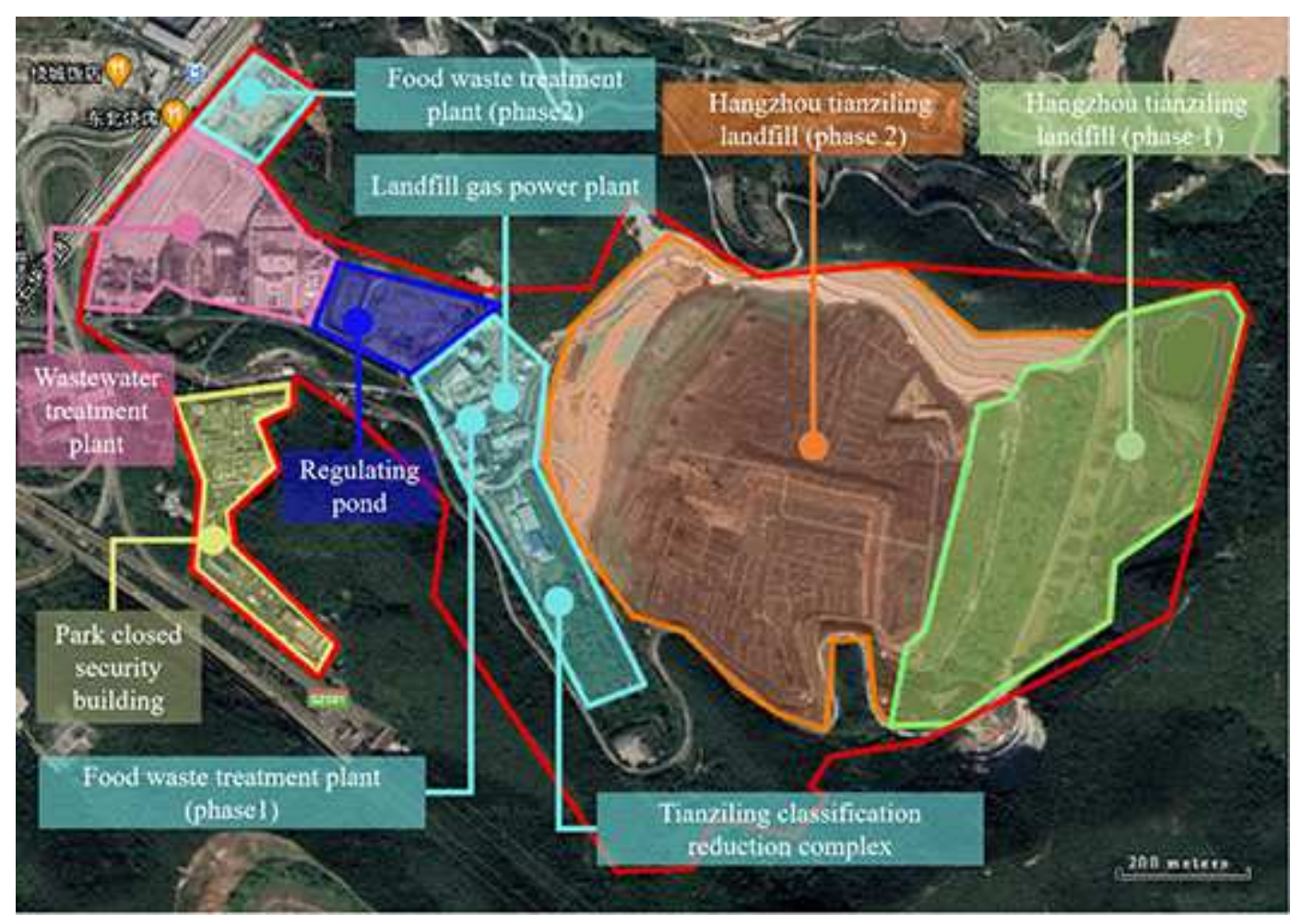

\section{Figure 1}

Floor plan of Hangzhou Tianziling Landfill, China. Note: The designations employed and the presentation of the material on this map do not imply the expression of any opinion whatsoever on the part of Research Square concerning the legal status of any country, territory, city or area or of its authorities, or concerning the delimitation of its frontiers or boundaries. This map has been provided by the authors. 


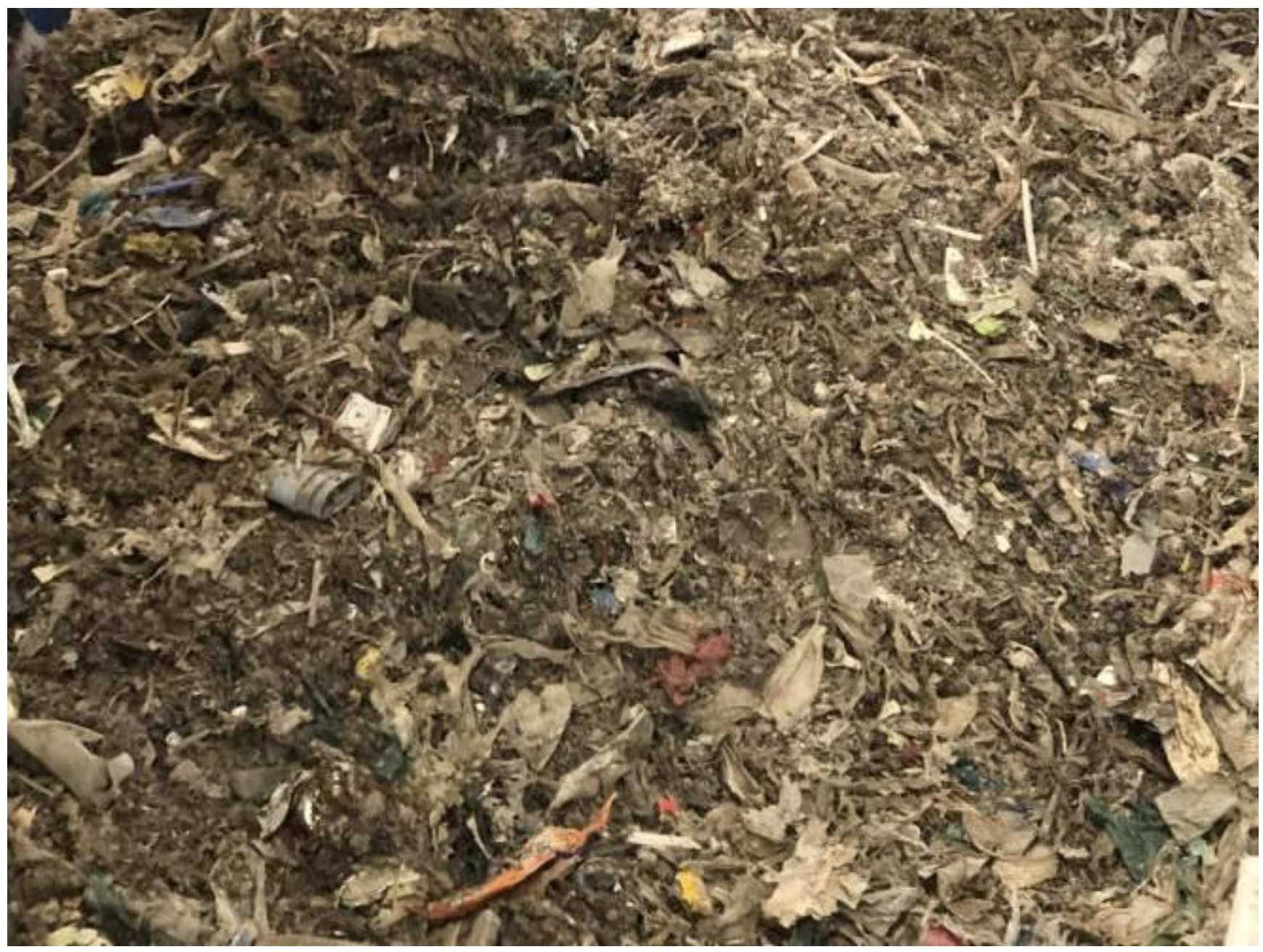

Figure 2

MBT waste original materials. 


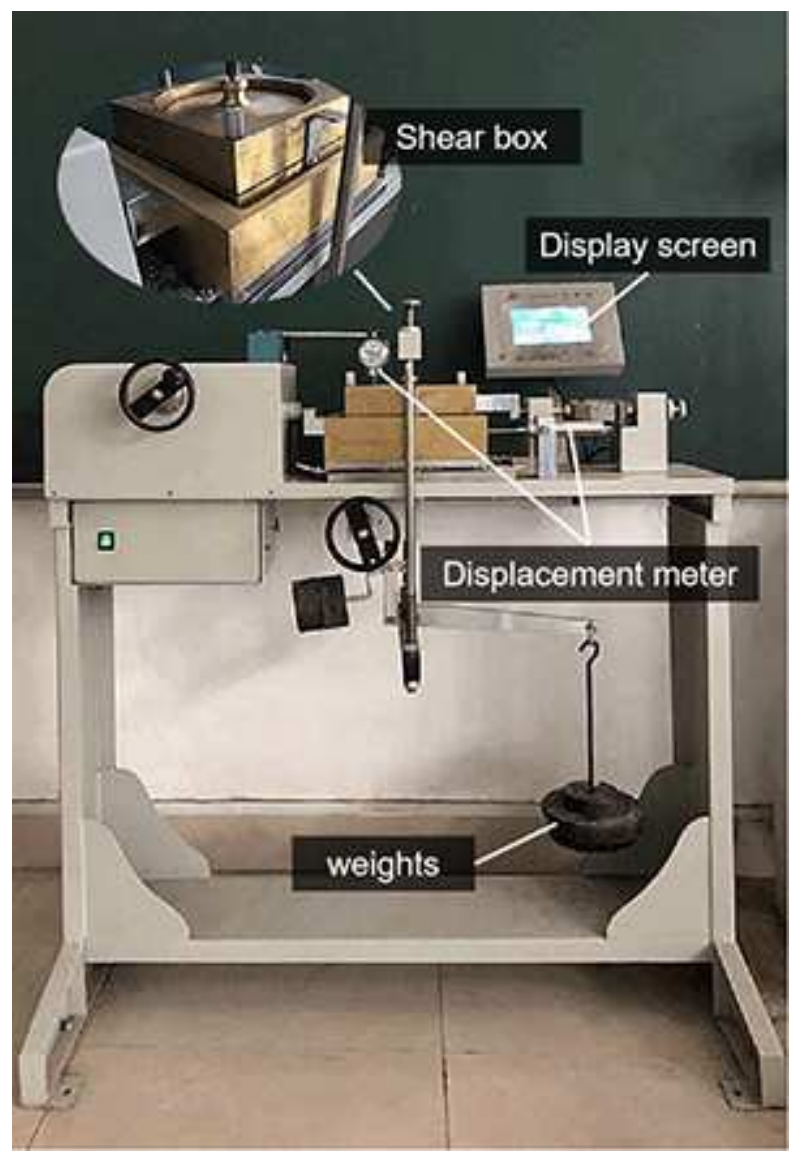

Figure 3

Direct shear test apparatus. 


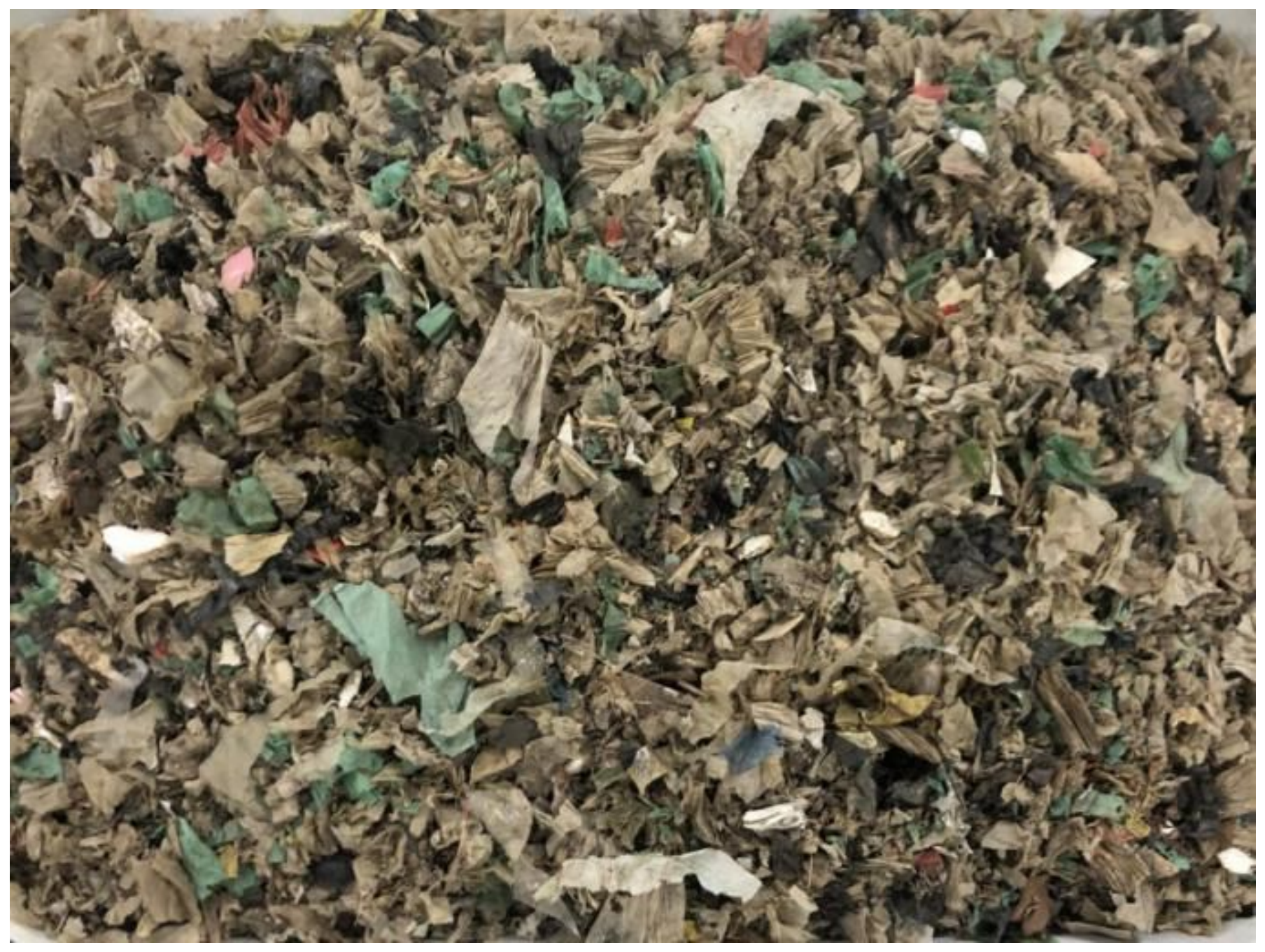

Figure 4

MBT waste test materials. 


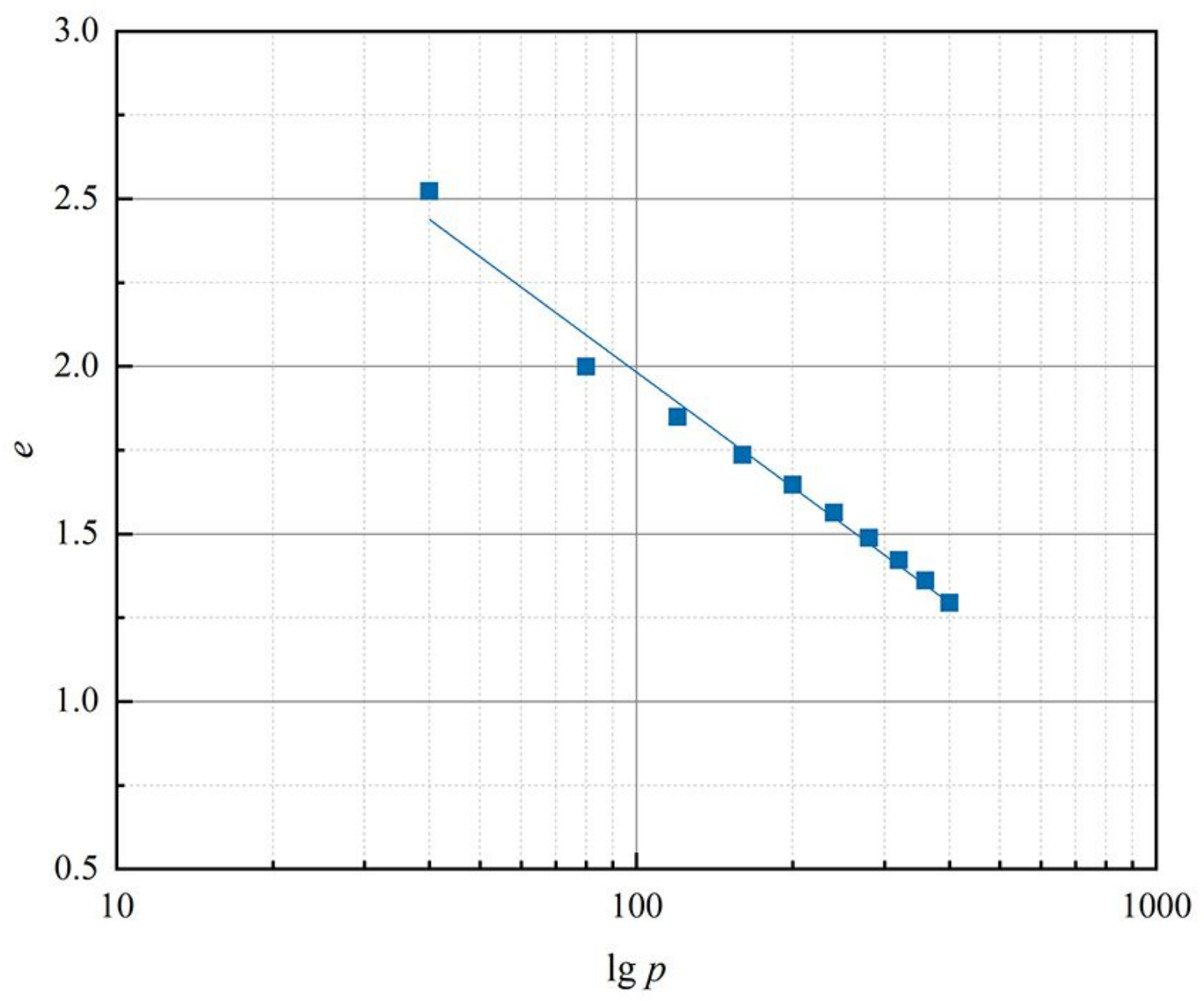

Figure 5

The relationship between the porosity ratio (e) and the logarithm of vertical pressure ( $\lg p)$. 


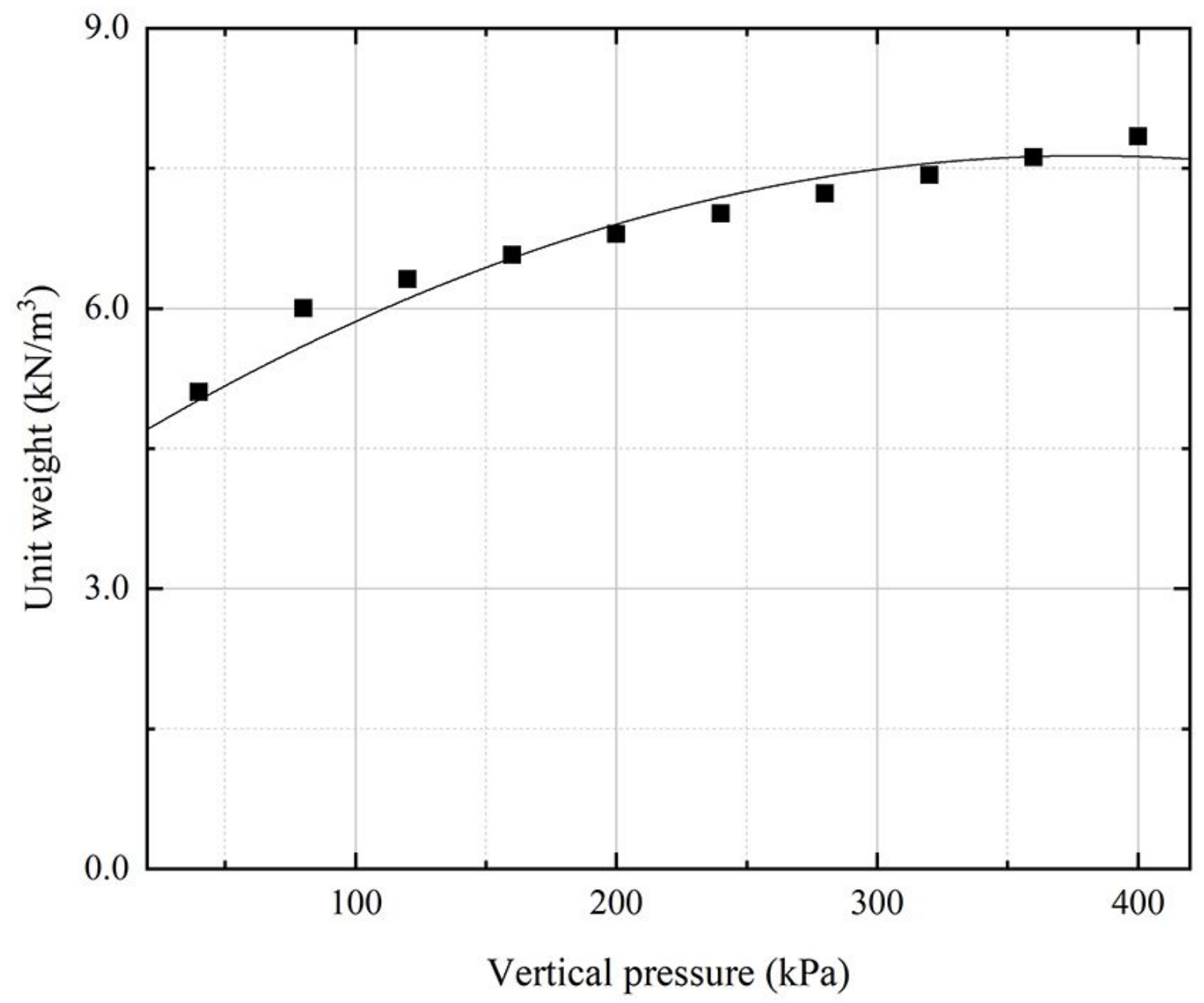

Figure 6

The relationship between the unit weight of the sample and the vertical pressure. 


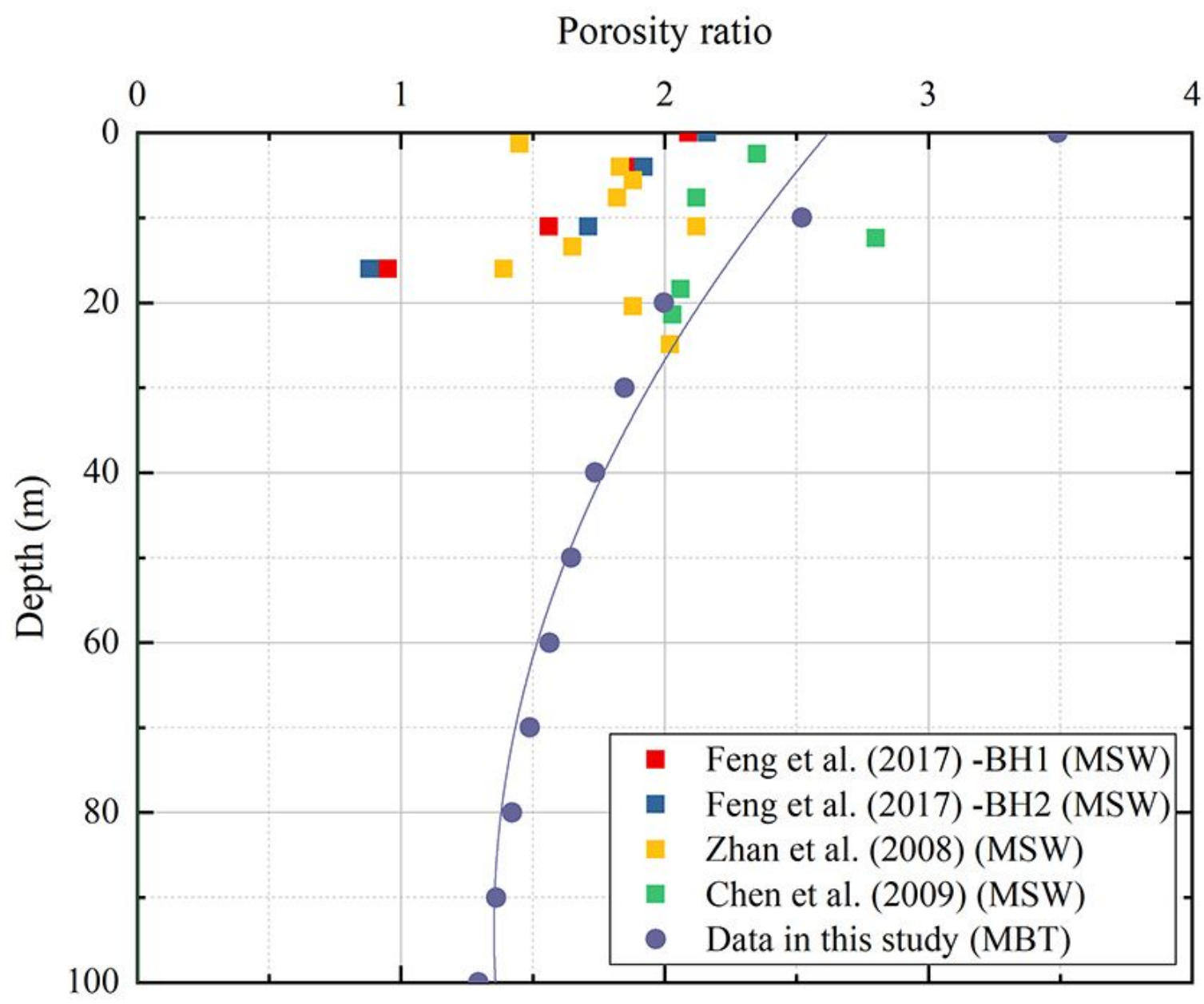

Figure 7

The porosity ratio of MSW and MBT waste varies with depth. 


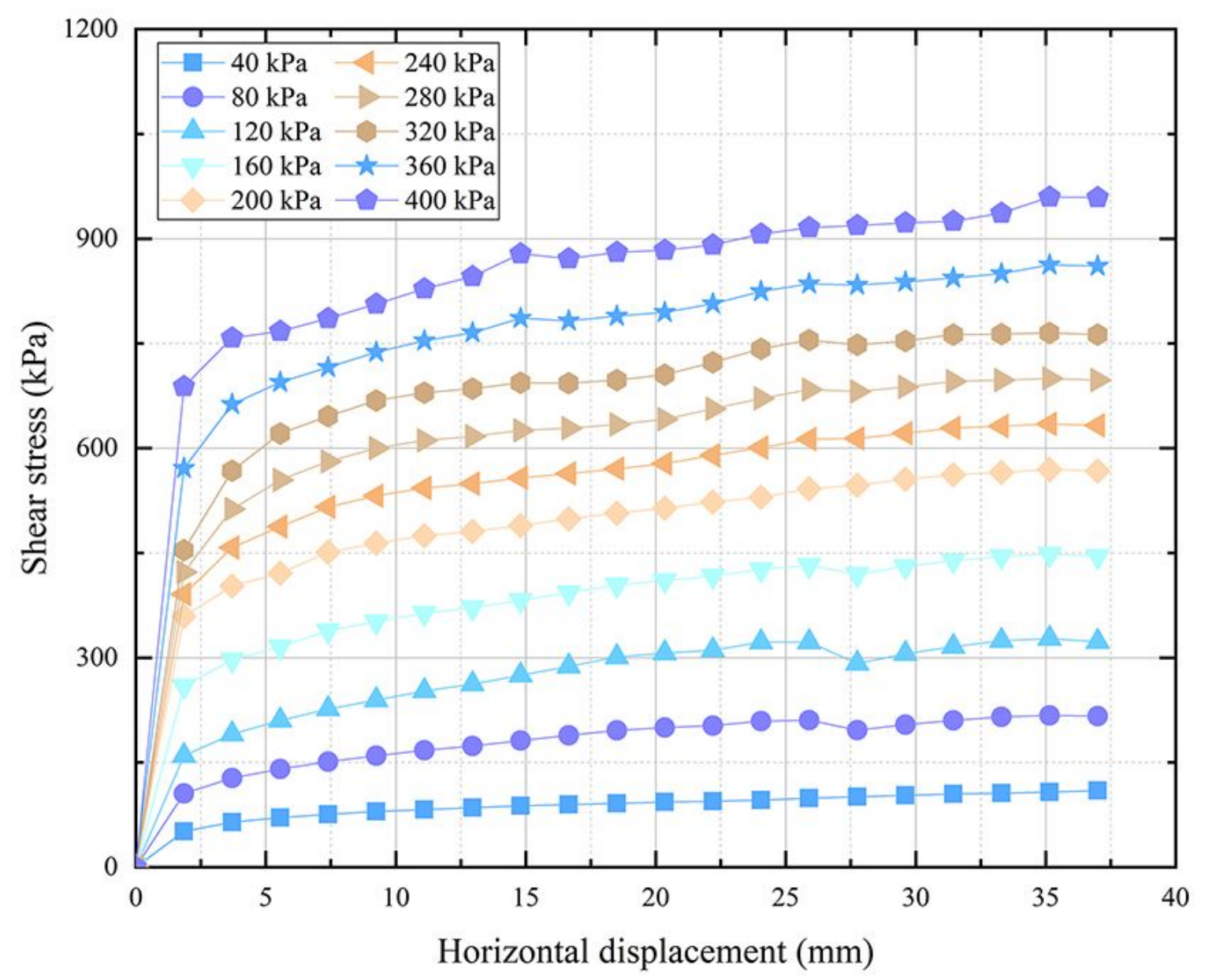

Figure 8

Shear stress-horizontal displacement graph (shearing rate is $5 \mathrm{~mm} / \mathrm{min}$ ). 


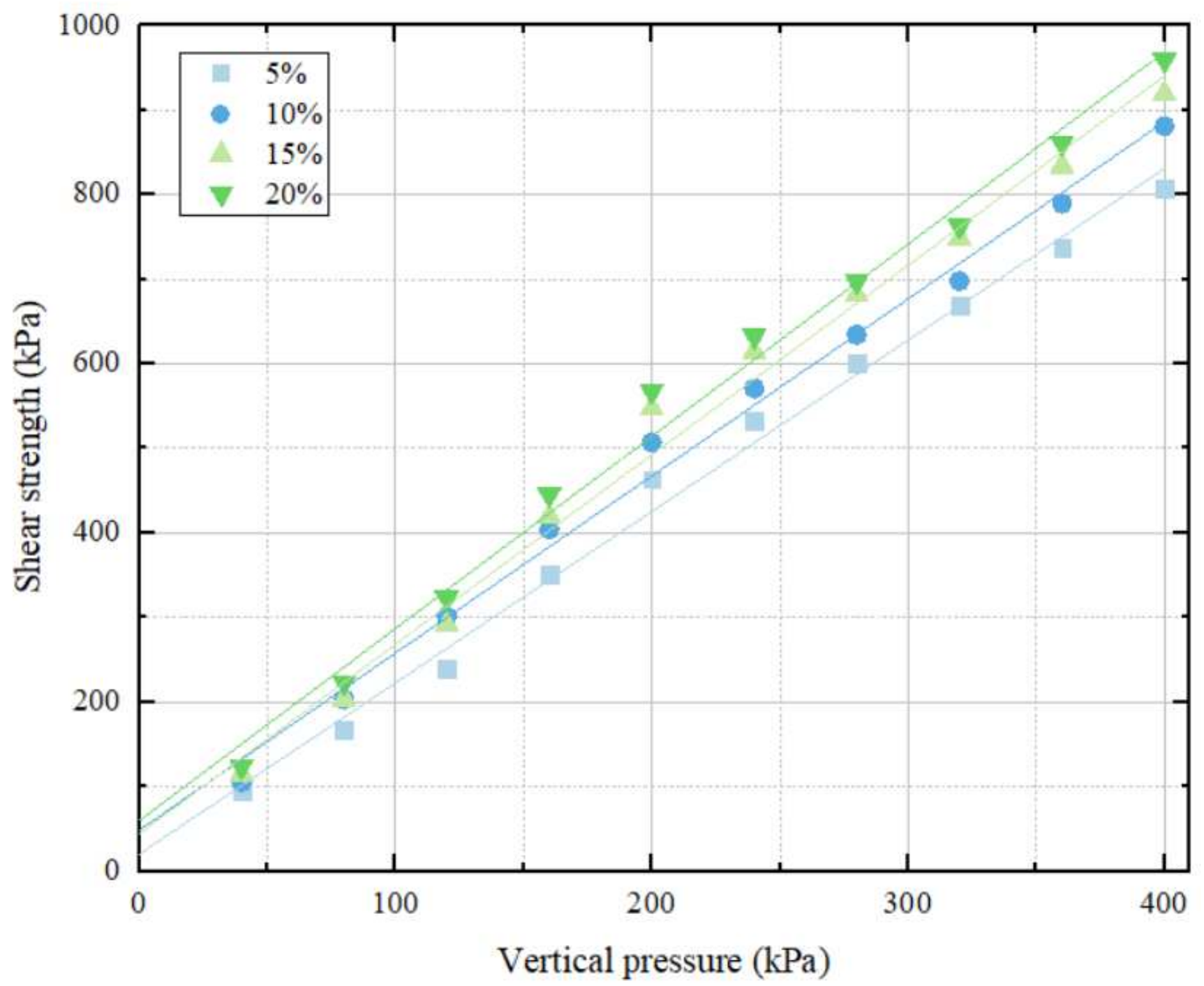

Figure 9

MBT waste shear strength envelope (shearing rate is $5 \mathrm{~mm} / \mathrm{min}$ ). 


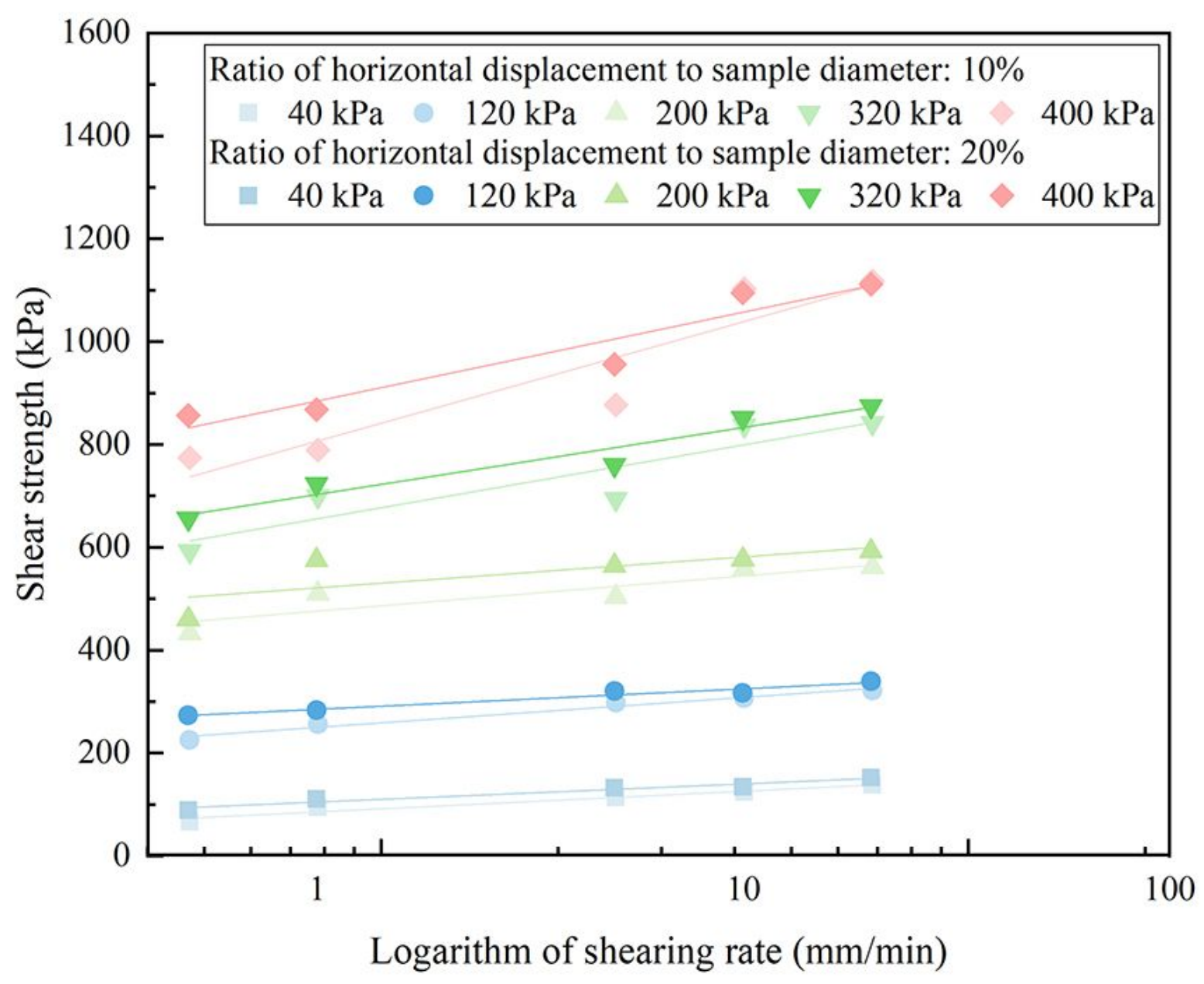

Figure 10

The relationship between shear strength and logarithm of shearing rate. 


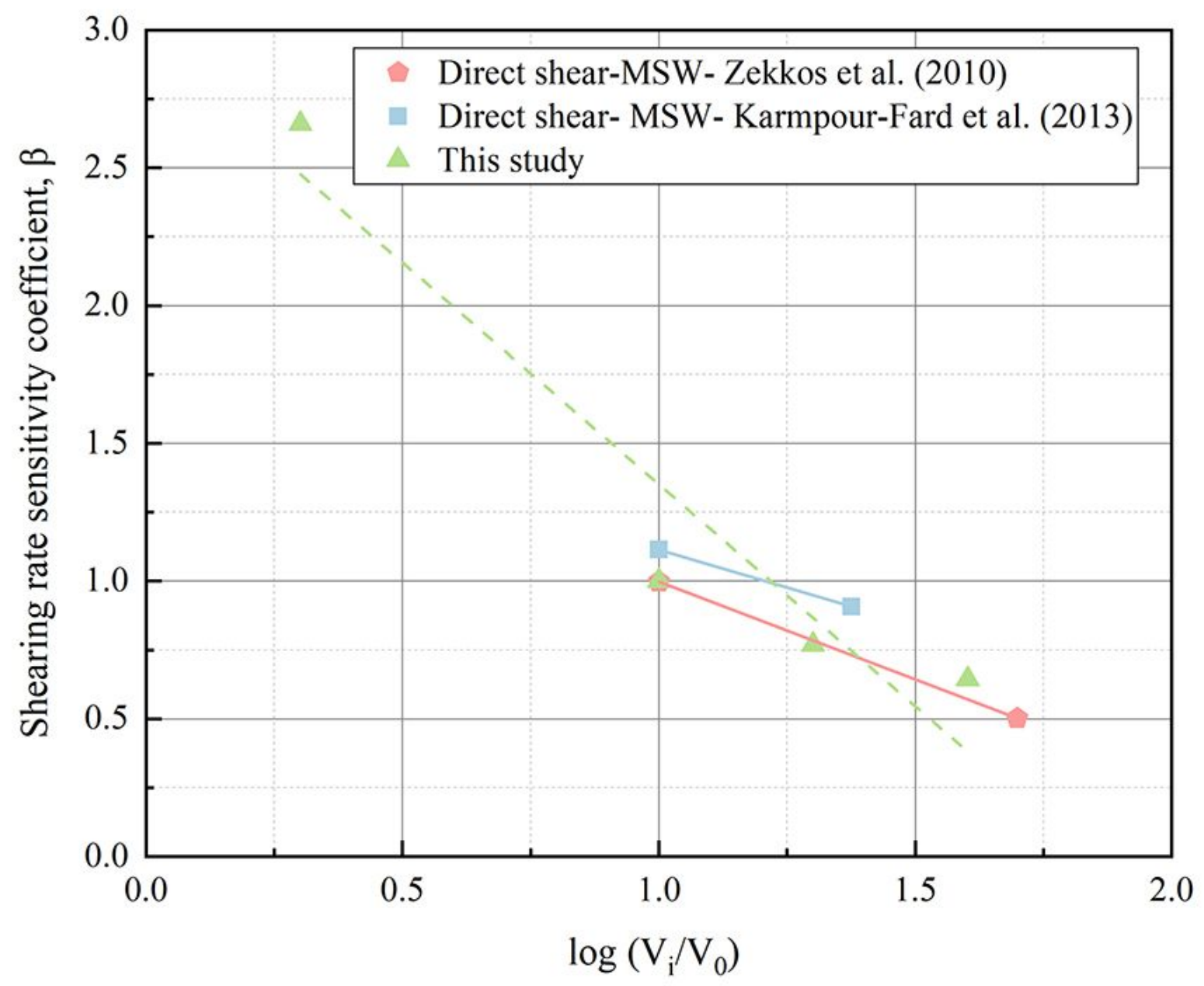

Figure 11

The shearing rate sensitivity coefficient of waste samples. 


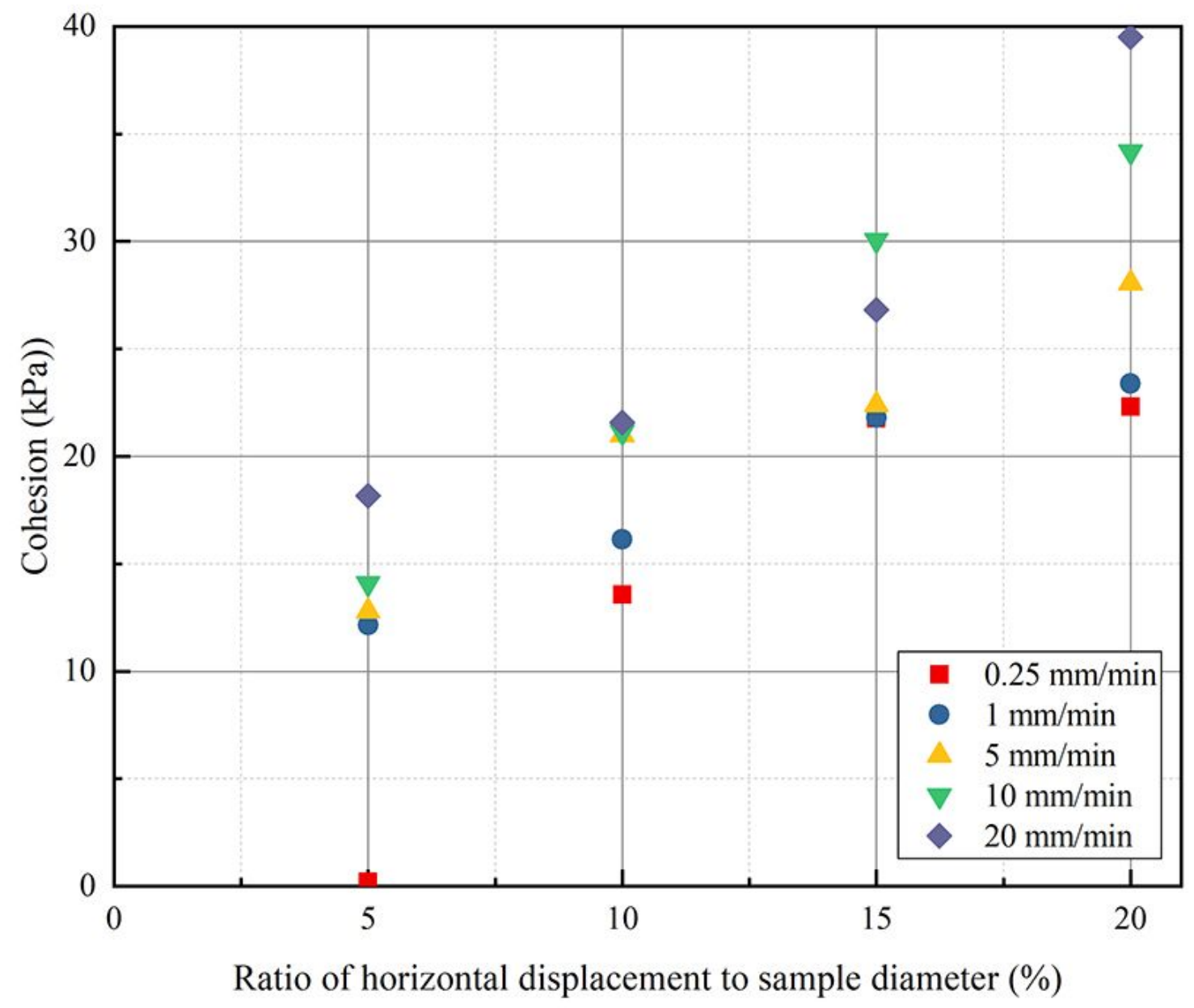

Figure 12

The relationship between cohesion and ratio of horizontal displacement to sample diameter. 


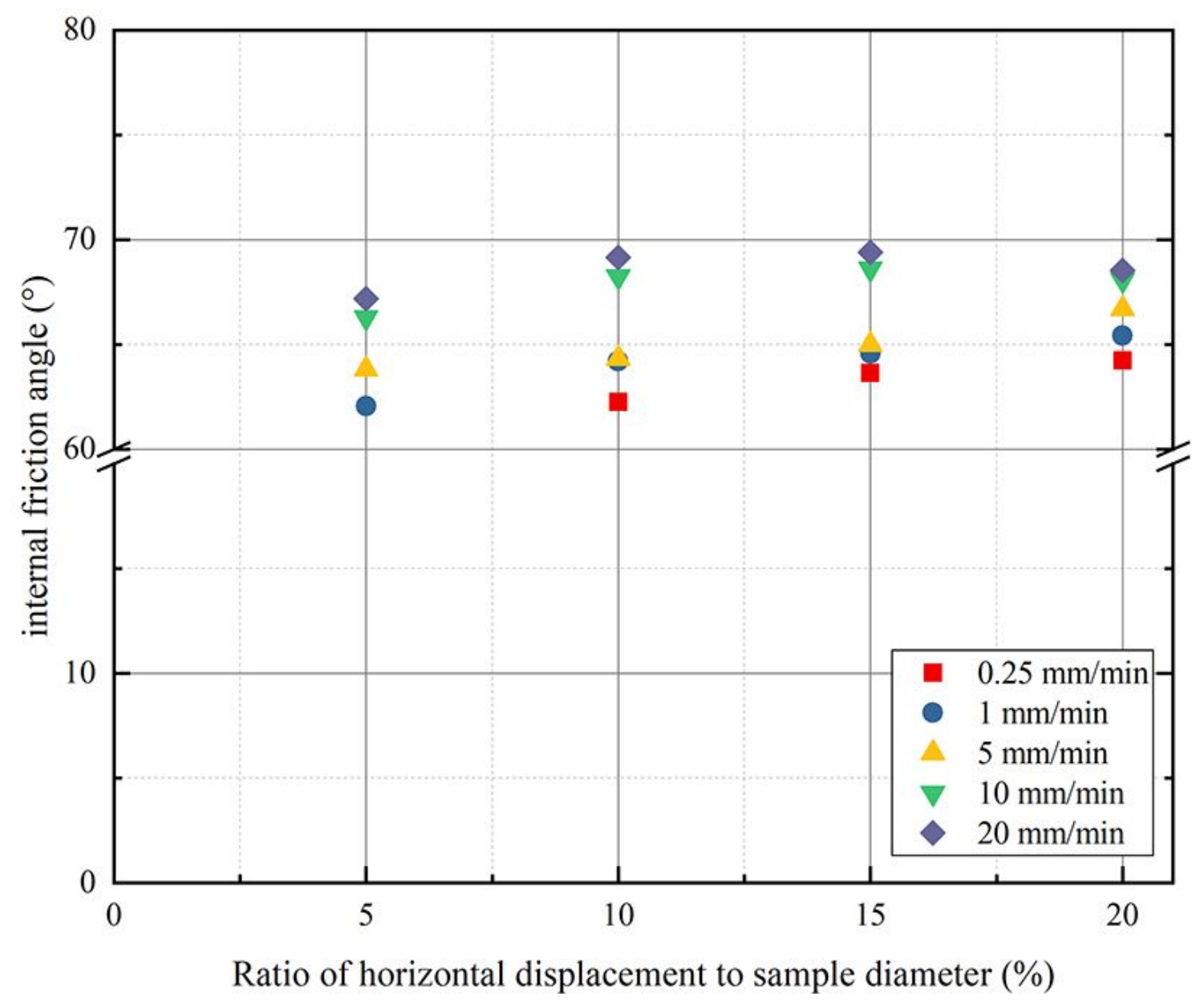

Figure 13

The relationship between internal friction angle and ratio of horizontal displacement to sample diameter. 


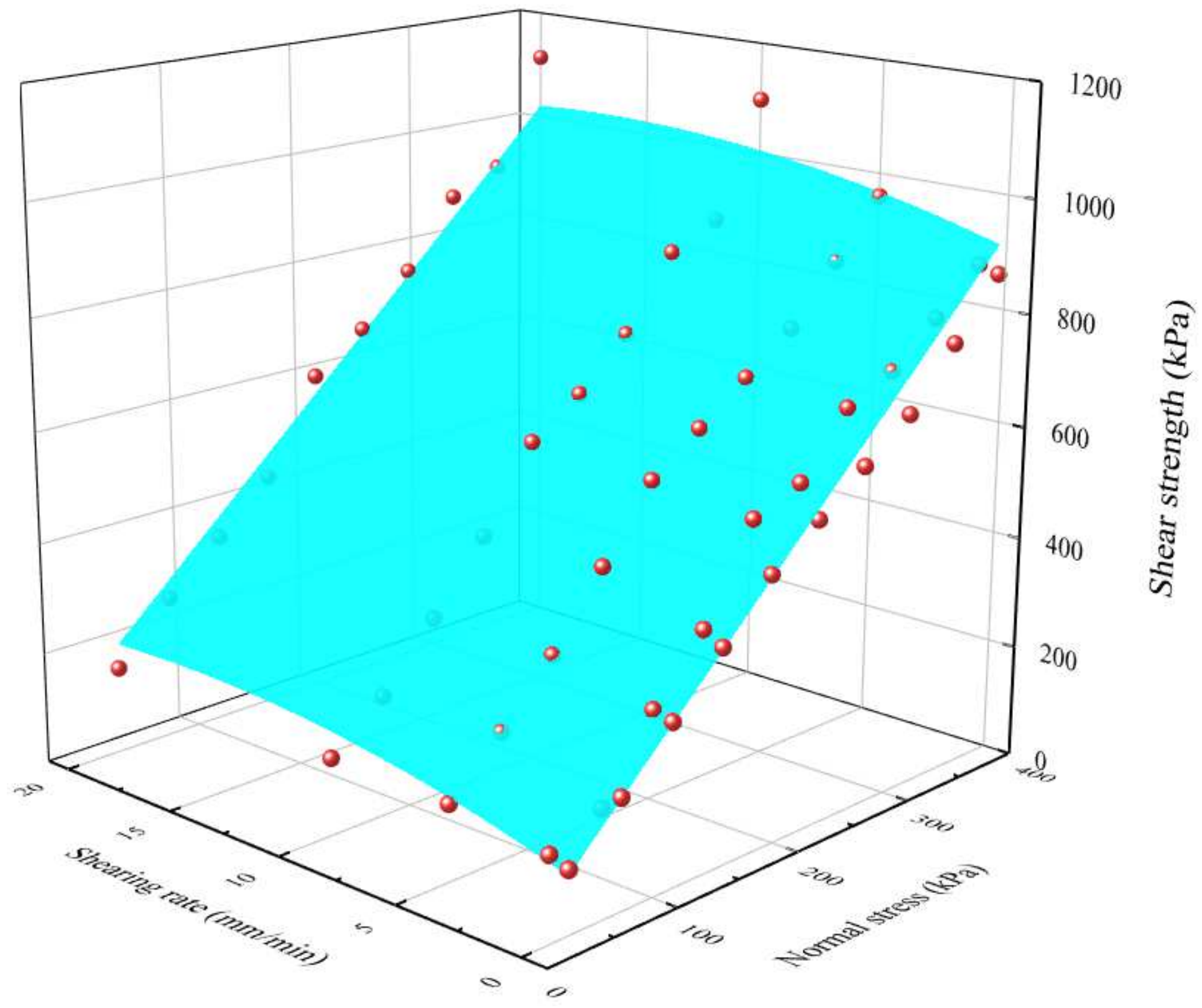

Figure 14

Shear strength fitting model. 


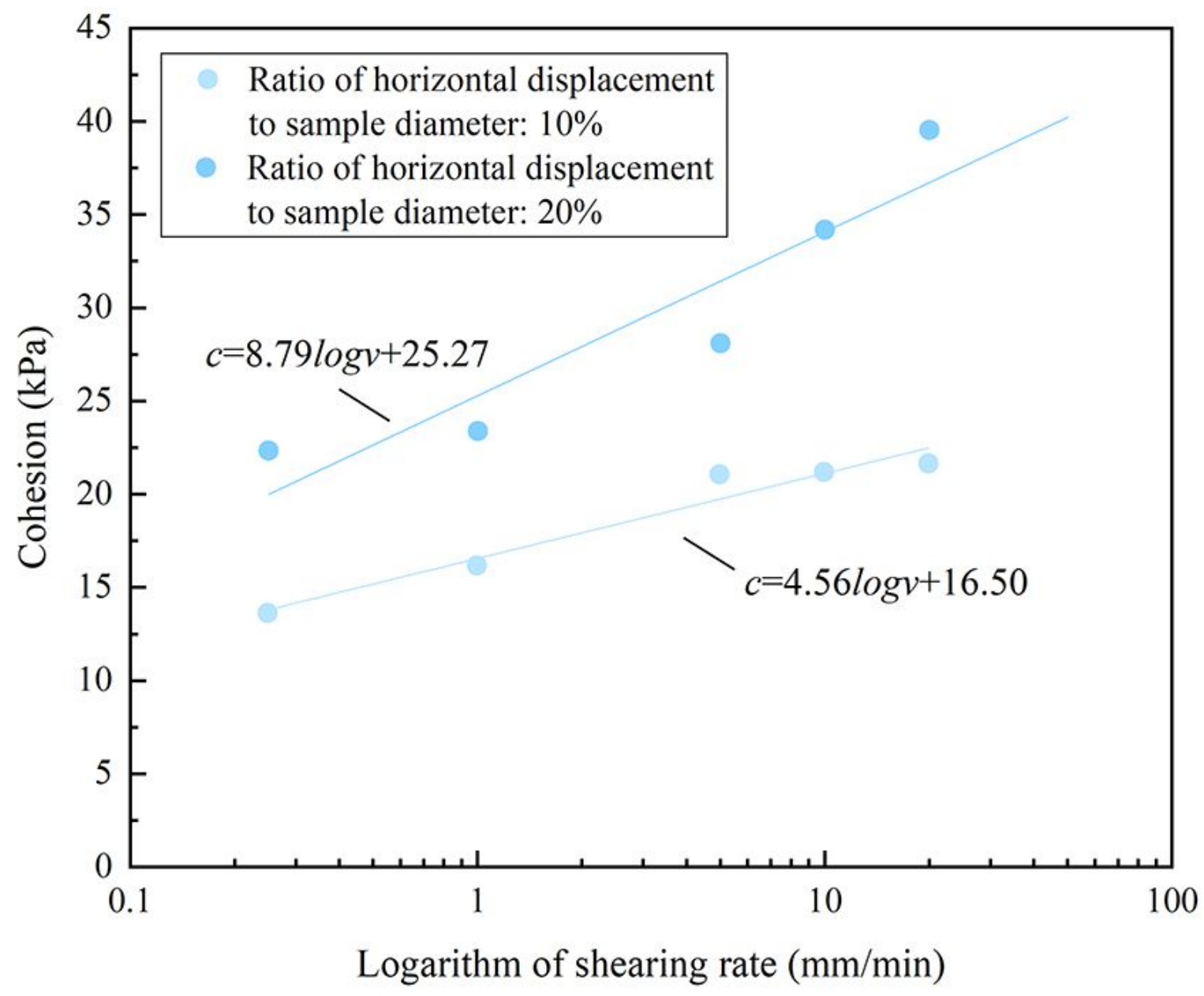

Figure 15

Relationship between cohesion and logarithm of shearing rate. 


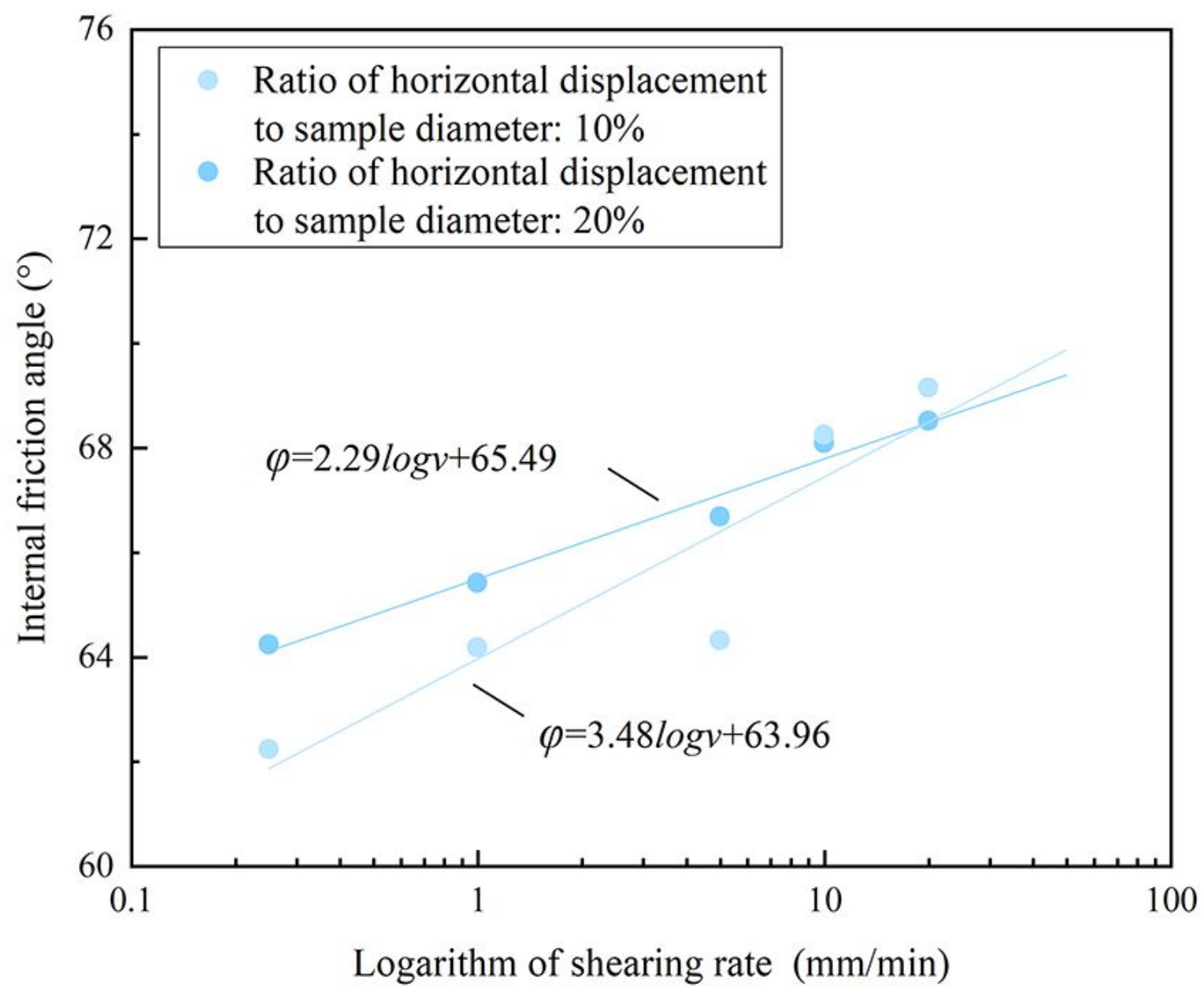

Figure 16

Relationship between internal friction angle and logarithm of shearing rate. 


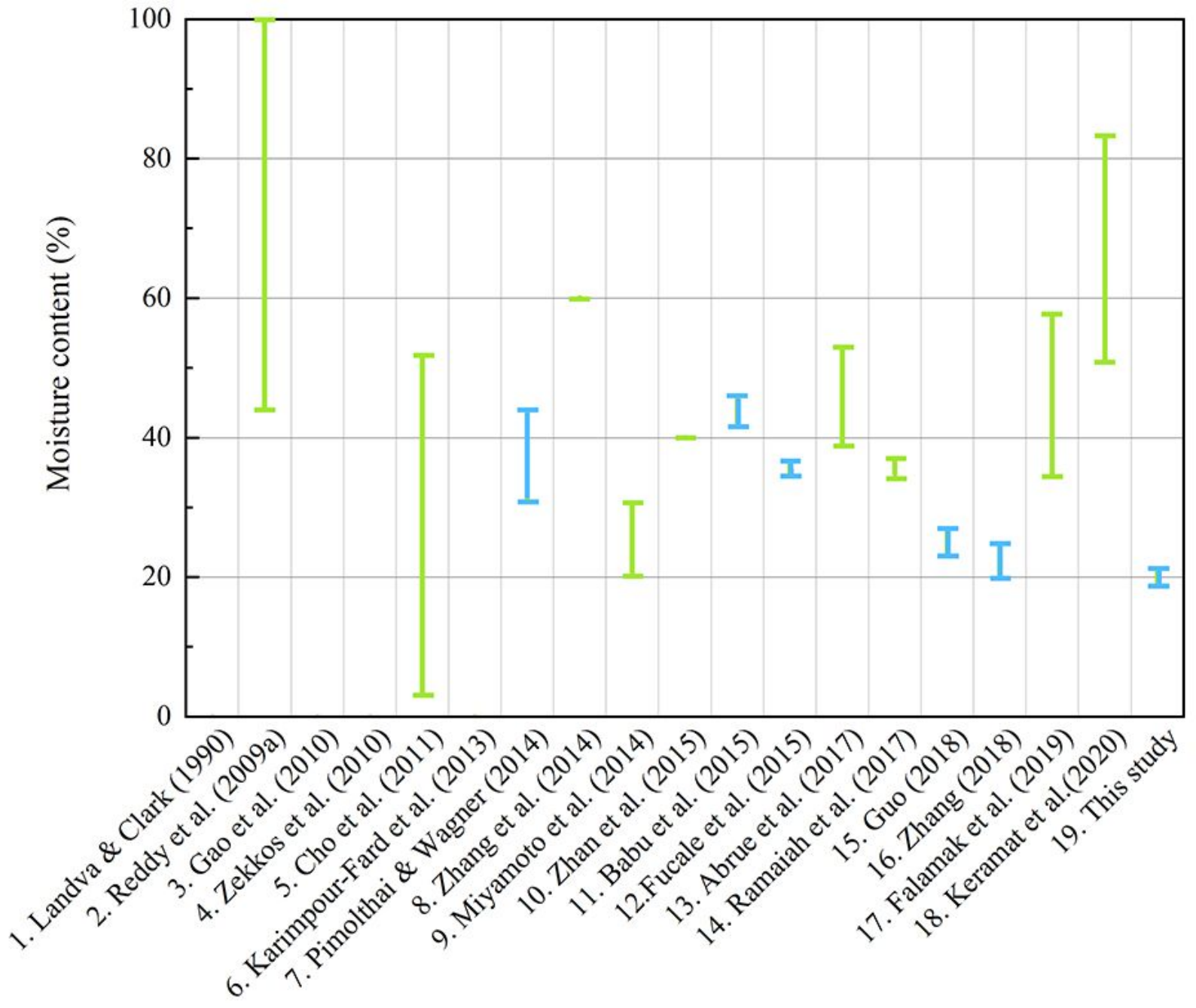

Figure 17

Moisture content of each reference sample (green - MSW, blue - MBT waste). 


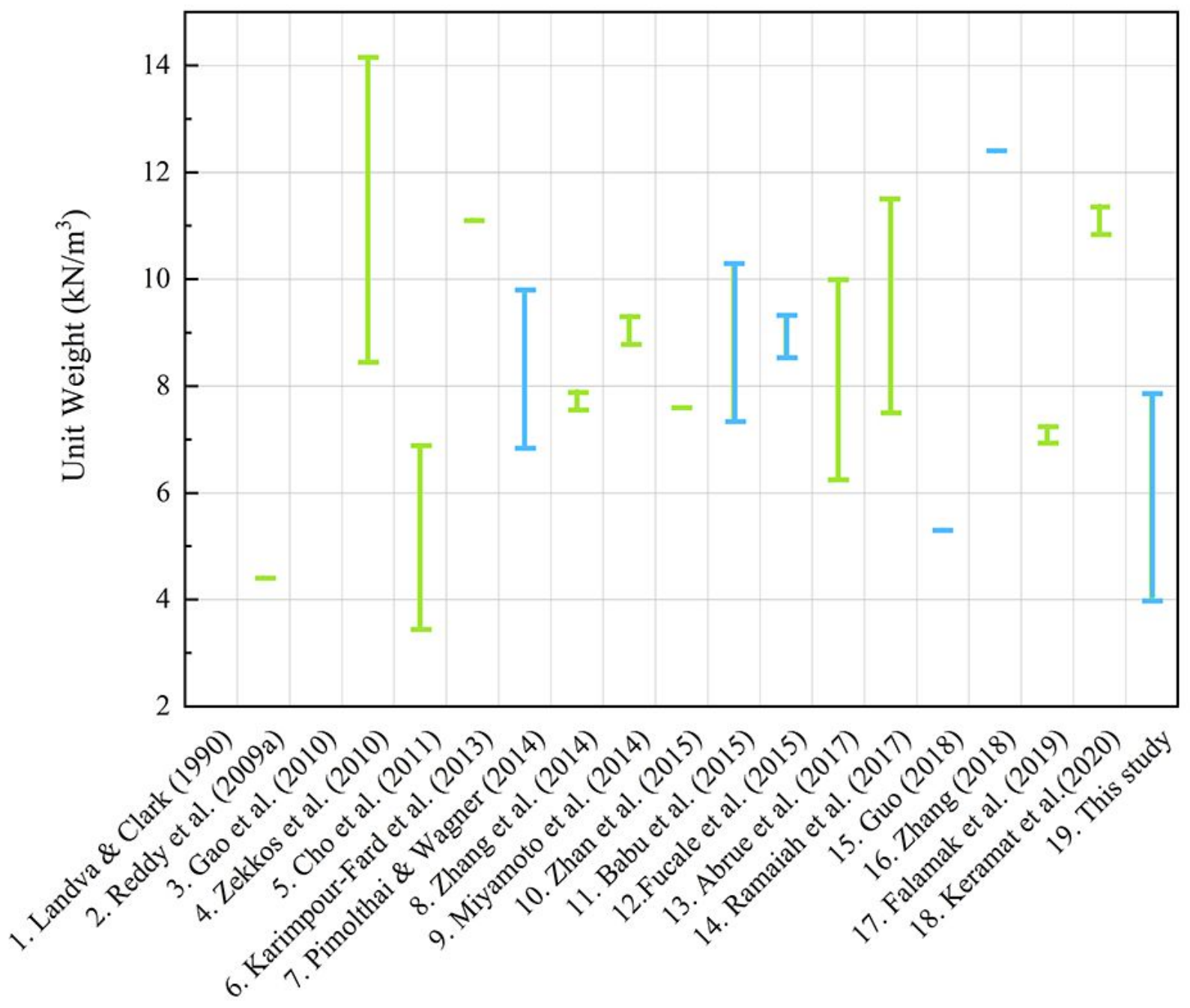

Figure 18

Unit weight of each reference sample (green - MSW, blue - MBT waste). 

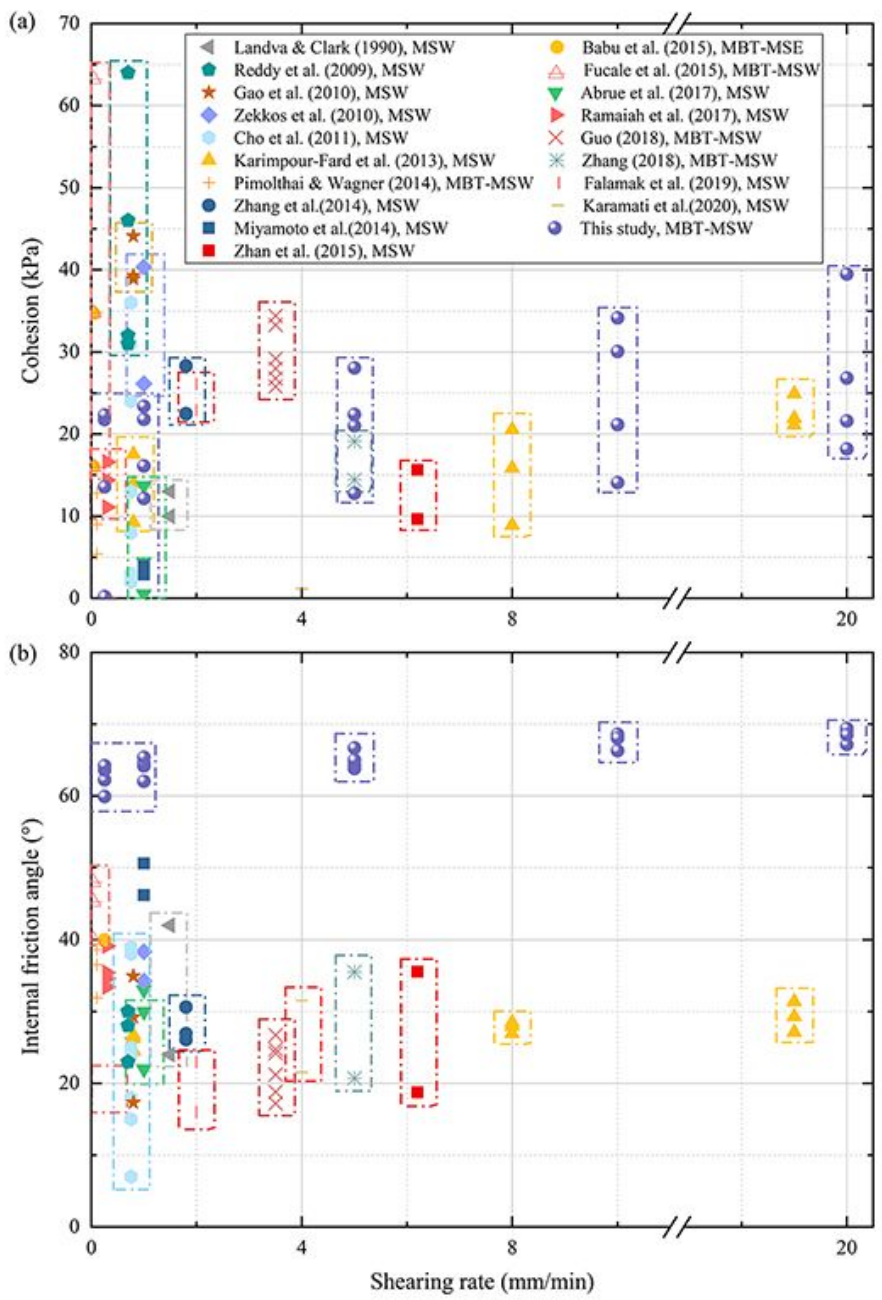

Figure 19

Comparison of shear strength parameters (a) the relationship between cohesion and shearing rate, (b) the relationship between internal friction angle and shearing rate. 